\title{
Loss of Fam 20c causes defects in the acinar and duct structure of salivary glands in mice
}

\author{
NAN MIAO ${ }^{1}$, YUANBO ZHAN ${ }^{2}$, YINGYING XU $^{1}$, HAOZE YUAN $^{1}$, CHUNLIN QIN $^{3}$, FENG LIN $^{4}$, \\ XIAOHUA XIE ${ }^{1,5}$, SEN MU $^{2}$, MENGTONG YUAN ${ }^{5}$, HAIBIN MU $^{1}$, SHOULI GUO $^{5}$, YING LI ${ }^{1}$ and BIN ZHANG ${ }^{1,6}$ \\ ${ }^{1}$ Institute of Hard Tissue Development and Regeneration, The Second Affiliated Hospital of Harbin Medical University, \\ Harbin, Heilongjiang 150001; ${ }^{2}$ Department of Periodontology and Oral Mucosa, The Second Affiliated Hospital of \\ Harbin Medical University, Harbin, Heilongjiang 150086, P.R. China; ${ }^{3}$ Department of Biomedical Sciences, \\ Texas A\&M University College of Dentistry, Dallas, TX 75246, USA; ${ }^{4}$ Department of General Surgery, \\ The First Affiliated Hospital of Harbin Medical University, Harbin, Heilongjiang 150086 ; ${ }^{5}$ The Second Affiliated Hospital \\ of Harbin Medical University; ${ }^{6}$ Heilongjiang Academy of Medical Sciences, Harbin, Heilongjiang 150001, P.R. China
}

Received November 26, 2018; Accepted March 1, 2019

DOI: 10.3892/ijmm.2019.4126

\begin{abstract}
Family with sequence similarity 20-member C (FAM20C), a recently characterized Golgi kinase, performs numerous biological functions by phosphorylating more than 100 secreted proteins. However, the role of FAM20C in the salivary glands remains undefined. The present study demonstrated that FAM20C is mainly located in the cytoplasm of duct epithelial cells in the salivary glands. Fam $20 c^{f / f}$; Mmtv-Cre mice were created in which Fam20c was inactivated in the salivary gland cells and observed that the number of ducts and the ductal cross-sectional area increased significantly, while the number of acinar cells was reduced. The granular convoluted tubules (GCTs) exhibited an accumulation of aberrant secretory granules, along with a reduced expression and altered distribution patterns of $\beta$ nerve growth factor, $\alpha$-amylase and bone morphogenetic protein (BMP) 4 . This abnormality suggested that the GCT cells were immature and exhibited defects in developmental and secretory functions. In accordance with the morphological alterations and the reduced number of acinar cells, FAM20C deficiency in the salivary glands significantly decreased the salivary flow rate. The $\mathrm{Na}^{+}$, $\mathrm{Cl}^{-}$and $\mathrm{K}^{+}$concentrations in the saliva were all significantly increased due to dysfunction of the ducts. Furthermore, Fam $20 \mathrm{c}$ deficiency significantly increased BMP2 and BMP7 expression, decreased BMP4 expression, and attenuated the canonical and
\end{abstract}

Correspondence to: Professor Bin Zhang or Dr Ying Li, Institute of Hard Tissue Development and Regeneration, The Second Affiliated Hospital of Harbin Medical University, 246 Xuefu Road, Nangang, Harbin, Heilongjiang 150001, P.R. China

E-mail: zhangbin@hrbmu.edu.cn

E-mail: liying@hrbmu.edu.cn

Key words: growth development, knockout mice, secretion, phosphorylation, saliva noncanonical BMP signaling pathways in the salivary glands. Collectively, the results of the present study demonstrate that FAM20C is a key regulator of acinar and duct structure and duct maturation and provide a novel avenue for investigating novel therapeutic targets for oral diseases including xerostomia.

\section{Introduction}

Salivary gland hypofunction is the inevitable result of Sjogren syndrome (1) or radiation therapy for head and neck cancer (2). There are different aspects of salivary gland hypofunction, including dry mouth, saliva secretion and saliva composition alterations, which seriously affect patients' quality of life and oral health $(3,4)$. In mice, salivary gland development begins with the thickening of the oral epithelium at embryonic day 11.5 , followed by successive branching and lumenization, with a functional arborized structure present at eight weeks following birth (5-7). Salivary gland morphogenesis is precisely controlled by regulatory genes and growth factors (7). Bone morphogenic proteins (BMPs) serve important roles in the morphogenesis of the submandibular gland (SMG) by regulating extracellular matrix (ECM) synthesis (8-10). Although the roles of BMPs in the salivary glands have been revealed, additional upstream regulatory proteins have yet to be studied.

Family with sequence similarity 20-member C (FAM20C), also known as dentin matrix protein 4, is a Golgi kinase that catalyzes the attachment of phosphates to serine in $\mathrm{S}-\mathrm{x}-\mathrm{E} / \mathrm{pS}$ motifs in secretory pathway proteins, including BMP4 (11-15). FAM20C can phosphorylate $>100$ secreted proteins, including specific ECM and transport proteins, proteases and protease inhibitors, and biologically active peptide hormones. The broad substrate spectrum of FAM20C suggests that this protein kinase participates in a wide range of biological processes, including cell migration and adhesion, ECM deposition and wound healing, in addition to biomineralization (16). FAM20C gene mutations in humans lead to Raine syndrome, which includes osteosclerotic bone dysplasia (17-20). In mice, Fam20c deletion results in 
hypophosphatemic rickets, increased levels of fibroblast growth factor 23 (FGF23) in the serum, reduced serum phosphorus levels and severe dentin, and enamel defects (21-24), indicating an essential role of FAM20C in bone and tooth development. Intriguingly, FAM20C is also likely to exert biological effects on processes other than mineralization due to its presence in mineralized tissues and soft organs, including salivary glands $(24,25)$. Given that teeth and SMGs share similarities in morphological and molecular features during development (26), it was hypothesized that FAM20C may serve a role in regulating the development and function of salivary glands.

In the present study, Fam20 $c^{f f f}$ mice were bred with mouse mammary tumor virus (Mmtv)-Cre mice that predominantly express the Cre recombinase in the striated ductal cells of the salivary glands, the mammary glands and the granular convoluted tubule (GCT) cells of the SMG (27-29). Fam $20 \mathrm{c}^{f f}$; Mmtv-Cre mice were generated in which Fam20c was specifically ablated in the mammary glands and salivary glands to assess the biological roles of FAM20C in the postnatal development and function of salivary glands.

\section{Materials and methods}

Ethics statement. All animal procedures in this study were approved by the Institutional Animal Care and Use Committee of Harbin Medical University (Harbin, China; approved protocol nos. SYDW2018-046) and performed in strict accordance with the National Institute of Health Guide for the Care and Use of Laboratory Animals.

Generation of Fam $20 c^{f f f} ;$ Mmtv-Cre mice. To generate Fam $20 \mathrm{c}$ salivary gland conditional knockout mice, 4 Fam $20 \mathrm{c}^{f f f}$ mouse (Department of Biomedical Sciences, Texas A\&M University College of Dentistry, Dallas, TX 75246, USA; age, 1 month) were first mated with $4 \mathrm{Mmtv}$-Cre mouse (Shanghai Biomodel Organisms Center Co., Ltd., Shanghai, China; age 8 weeks) and crossed the offspring of $20 \mathrm{Fam} 2 \mathrm{Oc}^{f /+} ; \mathrm{Mmtv}$-Cre mouse with 20 Fam $20 c^{f f f}$ mice to obtain 33 Fam $20 c^{f f f}$; Mmtv-Cre conditional knockout (cKO) mice, which were salivary gland conditional knockout mice. Postnatal days 0 mice $(1 \mathrm{~g})$ were selected as the starting point of observation, and the 5-day$(5 \mathrm{~g})$ and 8 -week-old $(40 \mathrm{~g})$ mice were selected to evaluate the progression of salivary defects in the cKO mice. 5 female Fam $20 \mathrm{c}^{f f f}$ and Fam $20 \mathrm{c}^{\mathrm{fff}} ; \mathrm{Mmtv}$-Cre mice and 6 male Fam $20 \mathrm{c}^{\mathrm{fff}}$ and Fam $20 \mathrm{c}^{\mathrm{ff}} ; \mathrm{Mmtv}$-Cre mice were analyzed for each age group. The mice were housed in a specific-pathogen free laboratory animal facility with $20-23^{\circ} \mathrm{C}, 40-60 \%$ humidity and a 12-h light/dark cycle. Standard laboratory chow and water were supplied ad libitum. Genotyping was performed by polymerase chain reaction (PCR) analyses using DNA extracted from mouse tails. The primer sequences and genotyping protocols used to confirm the presence of Fam $20 \mathrm{c}$ null alleles in the salivary glands of the conditional knockout mice were reported previously (30). Fam $20 c^{f f f}$ littermates of the Fam20 fff; Mmtv-Cre cKO mice were used as normal control mice (Ctrl mice); this procedure not only reduced the number of animals needed but also prevented the potential confounding effects of individual differences when comparing mice from different litters. The primer sequences (Invitrogen;
Thermo Fisher Scientific, Inc., Waltham, MA, USA) used are presented in Table I.

Histological analysis and calculation of the cross-sectional area. Salivary glands were fixed in $4 \%$ paraformaldehyde overnight at $4^{\circ} \mathrm{C}$ and embedded in paraffin. Sections $(4 \mu \mathrm{m})$ were prepared for hematoxylin and eosin (H\&E) staining, periodic acid-Schiff (PAS) staining, and immunohistochemical analyses. Subsequently, 3 stained sections were randomly selected for each gland from 5 males and 5 females at each age. Images from mouse salivary gland sections were captured by a digital camera installed on an inverted light microscope (Nikon Eclipse Ti-E; Nikon Corporation, Tokyo, Japan). The ductal cross-sectional area was calculated using image analysis software (Image-Pro Plus, version 7.0; Media Cybernetics, Inc., Bethesda, MD, USA). The insubstantial region of the gland was automatically omitted from all cross-sectional area calculations and the ducts were manually encircled. The acinar cross-sectional area was then estimated by subtracting the duct cross-sectional area from the gland cross-sectional area.

Electron microscope analysis. The dissected tissues were fixed in $2.5 \%$ glutaraldehyde overnight at $4^{\circ} \mathrm{C}$ and post-fixed with $1 \%$ osmium tetroxide at $4^{\circ} \mathrm{C}$ for $3 \mathrm{~h}$. Following dehydration and embedding in Spurr resin (Shanghai GenMed, Co., Ltd., Shanghai, China), the samples were cut into 70-nm-thick sections using an ultramicrotome (Leica Ultracut R; Leica Microsystems GmbH, Wetzlar, Germany). Ultrathin sections were double-stained with uranyl acetate and lead citrate at room temperature for $10 \mathrm{~min}$ each. The samples were examined with a transmission electron microscope (HITACHI H-7650; Hitachi, Ltd., Tokyo, Japan).

Immunohistochemical staining. For immunohistochemical staining, paraffin sections were treated with $3 \% \mathrm{H}_{2} \mathrm{O}_{2}$ to block endogenous peroxidase activity. Sodium citrate heat-induced (about $120^{\circ} \mathrm{C}$ ) antigen retrieval was used for all specimens except cytokeratin 7 antigen, which was retrieved by EDTA buffer. The sections were washed three times with PBS plus 0.1\% Tween, (Beyotime Institute of Biotechnology, Shanghai, China) for $5 \mathrm{~min}$ each. To avoid nonspecific immunoreactions, the sections were incubated with $10 \%$ normal goat or rabbit serum (Beyotime Institute of Biotechnology) and 3\% bovine serum albumin (BSA; Beyotime Institute of Biotechnology), followed by overnight incubation at $4^{\circ} \mathrm{C}$ with primary antibodies and incubation at room temperature for $1 \mathrm{~h}$ with biotinylated secondary antibodies. All antibodies are presented in Table II. Immunopositive reactions were visualized using 3,3'-diaminobenzidine tetrahydrochloride solution. Sections were counterstained with hematoxylin at room temperature for $1 \mathrm{~min}$ and the expression of target proteins was detected by the antibodies presented in Table II. Negative controls were included for all target proteins. The negative control group in which the primary antibody was replaced with PBS did not demonstrate any positive reactions. Images were captured using an inverted light microscope and analyzed using image analysis software (Image-Pro Plus, version 7.0; Media Cybernetics, Inc., Bethesda, MD, USA). The insubstantial region of the gland was automatically omitted. The 
Table I. List of primers for the genotyping and reverse transcription-polymerase chain reaction.

\begin{tabular}{lll}
\hline Gene & \multicolumn{1}{c}{ Forward primers } & \multicolumn{1}{c}{ Reverse primers } \\
\hline Floxed allele & a: TCCAGCTTGCTAGGGCTCTGACC & b: CTATGTCCAACGGCCGCAGCTT \\
& c: GTCCTGAGGGCTGACCCAAGACTA & \\
Mmtv-Cre transgene & AGCGATGGATTTCCGTCTCTGG & AGCTTGCATGATCTCCGGTATTGAA \\
Cre-loxP recombination & GTGGTCTCTGCCGCTGATGTACC & TTTGGGAGCCTATGTCCAACGGCC \\
Bmp2 & TGACTGGATCGTGGCACCTC & CAGAGTCTGCACTATGGCATGGTTA \\
Bmp4 & ACAATGTGACACGGTGGGAAAC & TGTGGGTGATGCTTGGGACTAC \\
Bmp7 & ACATCCGGGAGCGATTTGAC & TCCTCAGAAGCCCAGATGGTC \\
$\beta$-actin & AGAGGGAAATCGTGCGTGAC & CTCGTTGCCAATAGTGATGACC \\
\hline
\end{tabular}

BMP, bone morphogenic protein.

Table II. List of antibodies.

\begin{tabular}{|c|c|c|c|c|c|}
\hline Antibody & Cat. no., manufacturer & Source & Dilution (IHC) & Dilution (WB) & Dilution (IF) \\
\hline FAM20C & ab107079, Abcam & Rabbit & $1: 400$ & & $1: 200$ \\
\hline FAM20C & AV49490, Sigma-Aldrich & Rabbit & & $1: 1,000$ & \\
\hline AQP5 & ab78486, Abcam & Rabbit & $1: 200$ & & \\
\hline Cytokeratin 7 & ab181598, Abcam & Rabbit & $1: 8,000$ & & \\
\hline$\alpha$-Amylase & 3796s, CST & Rabbit & & $1: 1,000$ & \\
\hline$\beta-\mathrm{NGF}$ & ab6199, Abcam & Rabbit & $1: 500$ & & \\
\hline Bmp2 & 18933, Proteintech & Rabbit & & $1: 500$ & \\
\hline Bmp4 & ab39973, Abcam & Rabbit & $1: 200$ & $1: 1,000$ & \\
\hline Bmp7 & ab56023, Abcam & Rabbit & & $1: 1,000$ & \\
\hline panSmad1/5/9 & ab66737, Abcam & Rabbit & $1: 200$ & $1: 1,000$ & \\
\hline p-Smad1/5/9 & $13820, \mathrm{CST}$ & Rabbit & $1: 50$ & $1: 500$ & \\
\hline pan-Erk1/2 & $4695, \mathrm{CST}$ & Rabbit & $1: 200$ & $1: 1,000$ & \\
\hline p-Erk1/2 & 4370, CST & Rabbit & $1: 50$ & $1: 500$ & \\
\hline pan-P38 & $8690, \mathrm{CST}$ & Rabbit & $1: 200$ & $1: 1,000$ & \\
\hline p-P38 & 4511, CST & Rabbit & $1: 50$ & $1: 500$ & \\
\hline$\beta$-actin & 4970T, CST & Rabbit & & $1: 1,000$ & \\
\hline
\end{tabular}

WB, western blotting; IHC, immunohistochemistry; IF, immunofluorescence; p-, phosphorylated; BMP, bone morphogenic protein; Erk, extracellular signal regulated kinase; Smad, mothers against decapentaplegic homolog 9; AQP5, aquaporin 5; $\beta$-NGF, $\beta$ nerve growth factor. Sigma-Aldrich; Merck KGaA (Darmstadt, Germany); CST, Cell Signaling Technology, Inc. (Danvers, MA, USA); ProteinTech Group, Inc. (Chicago, IL, USA).

integrated option density (IOD) values were counted and statistically analyzed using Prism 3.0 (GraphPad Software, Inc., La Jolla, CA, USA).

Immunofluorescence (IF) microscopy. Frozen salivary gland tissue sections were fixed with cold acetone at $4^{\circ} \mathrm{C}$ for $10 \mathrm{~min}$ and blocked in PBS ( $\mathrm{pH} \mathrm{7.4)} \mathrm{containing}$ $5 \% \mathrm{BSA}$ for $20 \mathrm{~min}$ at room temperature. The sections were incubated with a primary antibody specific for FAM20C (cat. no. ab107079; Abcam, Cambridge, UK) overnight at $4{ }^{\circ} \mathrm{C}$, followed by incubation with tetramethylrhodamine-conjugated secondary antibodies (Zhongshan Jinqiao Biological Technology, Co., Ltd., Beijing, China) at room temperature for $1.5 \mathrm{~h}$ and the nuclei were stained with 4',6-diamidino-2-phenylindole (Invitrogen; Thermo Fisher
Scientific, Inc.) at room temperature for $5 \mathrm{~min}$. The slides were examined and photographed with a fluorescence microscope (Nikon E800; Nikon Corporation) equipped with a digital camera (1200F; Nikon Corporation) and image acquisition software (ACT-1; Nikon Corporation). Antibody details can be found in Table II.

PCR and primers. Quantitative PCR (qPCR) was performed to evaluate the alterations in gene expression in Fam $20 \mathrm{c}$ conditional knockout mice. Total RNA was extracted from the salivary glands with TRIzol (Invitrogen; Thermo Fisher Scientific, Inc.) according to the manufacturer's protocol. The RNA concentrations were measured by a Nanovue spectrophotometer (GE Healthcare Life Sciences, Marlborough, MA, USA) and converted into cDNA using a real-time SYBR 
Premix Ex Taq ${ }^{\mathrm{TM}}$ kit (Takara Bio Inc., Otsu, Japan) on an MxPro-Mx3000P real-time PCR system (Stratagene; Agilent Technologies, Inc., Santa Clara, CA, USA). The reverse transcription conditions were as follows: $37^{\circ} \mathrm{C}$ for $15 \mathrm{~min}$ followed by $85^{\circ} \mathrm{C}$ for $5 \mathrm{sec}$. qPCR conditions were as follows: $95^{\circ} \mathrm{C}$ for $2 \mathrm{~min}$, followed by 40 cycles of $95^{\circ} \mathrm{C}$ for $15 \mathrm{sec}$ and $60^{\circ} \mathrm{C}$ for $30 \mathrm{sec}$. The primer sequences (Invitrogen; Thermo Fisher Scientific, Inc.) for the genes used in this study are listed in Table I. $\beta$-actin was used as an internal standard to calculate relative gene expression levels with the $2^{-\Delta \Delta c q}$ method (31).

Western immunoblotting (WB). Total protein was extracted from the salivary glands by using cold radioimmunoprecipitation assay lysis buffer (Beyotime Institute of Biotechnology), that contained Benzonase nuclease, phenylmethylsulfonyl fluoride, a protease inhibitor cocktail and a phosphatase inhibitor. The protein concentration was determined with a bicinchoninic acid (BCA) protein assay (Beyotime Institute of Biotechnology). A total of $40 \mu \mathrm{g}$ of sample from mouse salivary glands was separated by SDS-PAGE (10-12\%) and transferred to polyvinylidene difluoride membranes (EMD Millipore, Bedford, MA, USA). Following blocking with 5\% nonfat dry milk (Beyotime Institute of Biotechnology) at room temperature for $1 \mathrm{~h}$, the membranes containing significant proteins were incubated with primary antibodies at $4^{\circ} \mathrm{C}$ overnight. All antibodies used in this study are listed in Table II. Subsequently, the membranes were incubated with a horseradish peroxidase-conjugated antibody (Zhongshan Jinqiao Biological Technology, Co., Ltd., Beijing, China) for $1.5 \mathrm{~h}$ at room temperature, followed by detection with an enhanced chemiluminescence kit (Biosharp, Hefei, China) according to the manufacturer's protocol. The immunoreactive bands were captured with SmartChemi ${ }^{\mathrm{TM}}$ I (Beijing Sage Creation Science, Co., Beijing, China). The band density was determined using ImageJ 1.46r (National Institutes of Health, Bethesda, MA, USA) and normalized to $\beta$-actin. Each experiment was repeated three times.

Collection and compositional analysis of saliva. The mice were weighed and injected intraperitoneally with carbachol $(0.25 \mathrm{mg} / \mathrm{kg}$ of body weight) and were then injected intraperitoneally with pilocarpine $(10 \mathrm{mg} / \mathrm{kg}$ of body weight) (Aladdin Shanghai Biochemical Technology Co., Ltd., Shanghai, China; P129614) as previously described (32). A total of 2 min following pilocarpine injection, the total saliva was collected in calibrated glass capillary tubes on ice at intervals of 5, 10 and $15 \mathrm{~min}$ and injected into pre-weighed tubes on ice; the collected saliva was then placed into pre-weighed tubes and stored at $-80^{\circ} \mathrm{C}$. The flow rate was calculated as $\mu \mathrm{g}$ of saliva per normalized body weight. The total protein concentration of saliva was determined by a BCA assay (Beyotime Institute of Biotechnology). The concentration of $\mathrm{Na}^{+}$and $\mathrm{K}^{+}$ in the saliva was analyzed by an ion chromatography system (DIONEX, ICS-3000; Thermo Fisher Scientific, Inc.), and $\mathrm{Cl}^{-}$ activity was measured with an optical emission spectrometer (Optima, 5300DV; Optima, Inc., Tokyo, Japan).

Measurement of circulating androgen levels. Serum testosterone was measured by the ELISA method with a testosterone parameter assay kit (R\&D Systems, Minneapolis, MN, USA; cat. no. SKGE010) according to the manufacturer's protocol.
Statistical analysis. Data are presented as the mean \pm standard deviation of three independent experiments. Statistical testing was performed using Prism 3.0 (GraphPad Software, Inc., La Jolla, CA, USA). All statistical analyses were conducted by one-way analysis of variance followed by Tukey's test for multiple comparisons. $\mathrm{P}<0.05$ was considered to indicate a statistically significant difference.

\section{Results}

Verification of FAM20C expression and inactivation in mouse salivary glands. Genotyping PCR was performed with genomic DNA extracted from mouse tails. Using forward primer a and reverse primer $\mathrm{b}$ (Table I), the wild-type allele gave rise to a fragment of $500 \mathrm{bp}$, while a $400 \mathrm{bp}$ fragment was generated from the floxed allele. The $\mathrm{Mmtv}$-Cre recombinase gene gave rise to a 272 bp band; the conditional cKO mouse contained the Mmtv-Cre allele (reflected by the presence of the $272 \mathrm{bp}$ PCR product) and the recombined allele that gave rise to a PCR fragment of $260 \mathrm{bp}$ when forward primer a and reverse primer c (Table I) were employed for PCR analyses (Fig. 1A).

Immunohistochemistry (IHC) and IF staining were used to determine the expression and distribution of FAM20C in the salivary glands of normal control mice and to assess whether FAM20C was absent in cKO mice (Fig. 1B and C). Previous studies $(12,17,30,33)$ demonstrated that FAM20C was expressed in mineralized tissues. However, the expression and distribution of FAM20C in salivary glands have not been studied. In the present study the expression of FAM20C in the submandibular gland (SMG), parotid gland (PG) and sublingual gland (SLG) was identified. In the SMG of the control mice, FAM20C was expressed in the cytoplasm of cells of the intercalated duct (ID), striated duct (SD) and excretory duct (ED), but granular convoluted tubule (GCT) cells, which are situated between the striated and IDs, expressed a much higher level of FAM20C. In the PG and SLG, the immunostaining signal for FAM20C was also identified in the ductal cells. Furthermore, the signal for FAM20C was not observed in the corresponding components in the cKO mice. The negative staining demonstrated that FAM20C was effectively nullified in the salivary glands of the $\mathrm{cKO}$ mice (Fig. 1C).

Conditional inactivation of Fam20c leads to morphological and structural alterations in the salivary glands. $\mathrm{H} \& \mathrm{E}$ staining was performed to determine whether the conditional inactivation of Fam20c leads to morphological and structural alterations in the salivary glands. The tissues were processed at almost the same level. At postnatal days 0 and 5, when there was no sex difference in the SMG and the GCTs did not appear, the SMG of normal control mice was composed of multiple lobules separated by thin septa and consisted of acinar cells and few ductal structures. However, the SMG of cKO mice contained smaller lobules, prominent ductal structures and more mesenchymal tissue. The number of ducts was also increased in the cKO mice (Fig. 2A). At 8 weeks following birth, the GCTs in the SMG of male mice were more abundant than the GCTs in female mice due to the effects of androgens (34). In the SMG of 8-week-old mice, the cross-sectional area occupied by acinar cells in cKO mice was significantly decreased $(\mathrm{P}<0.01)$ and the mesenchyme was increased. The SMG of normal 
A

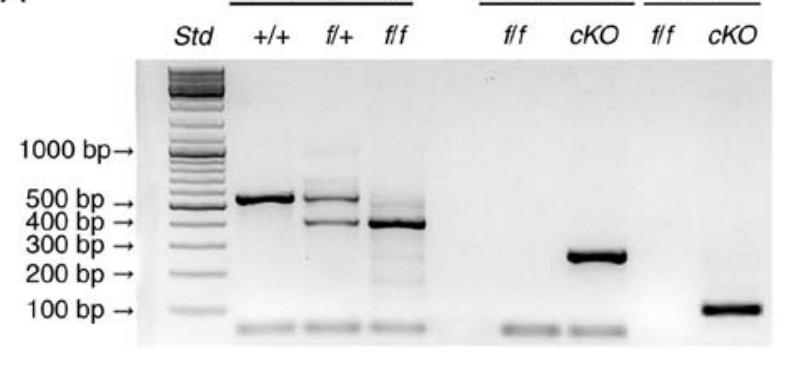

C
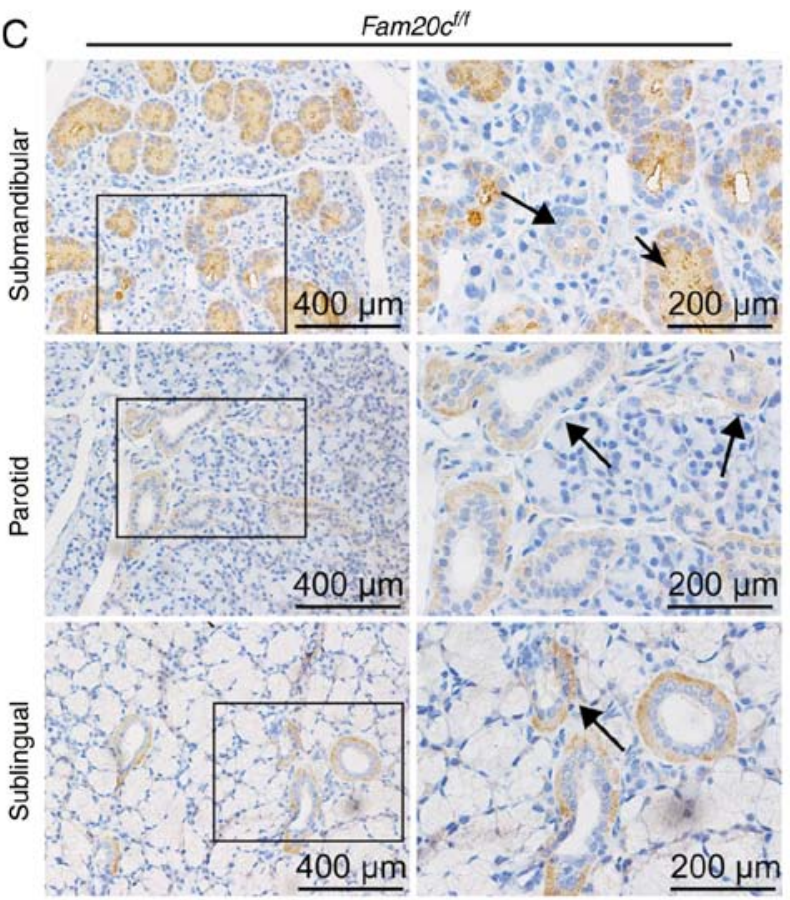

B

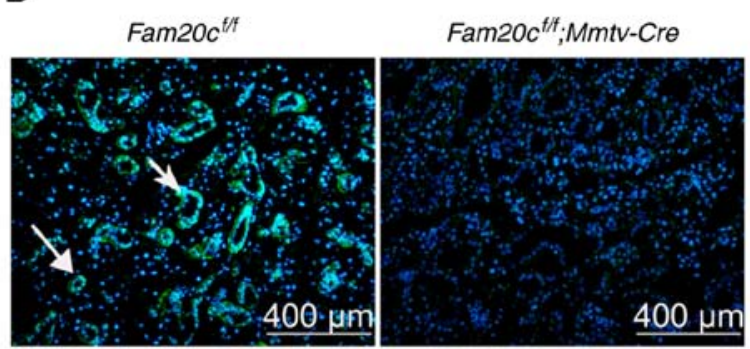

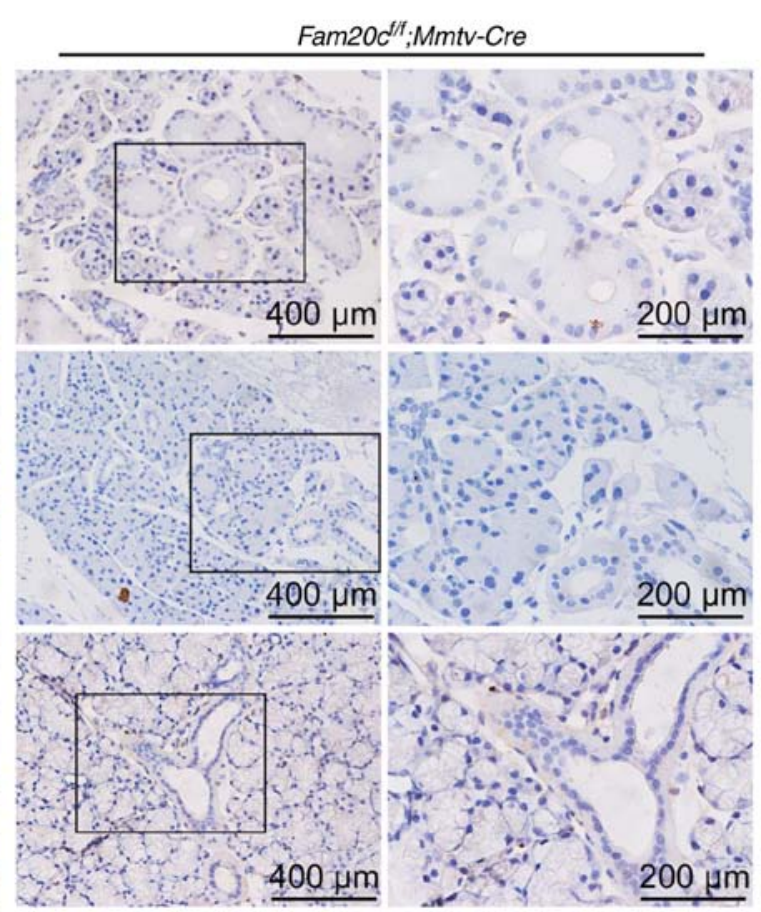

Figure 1. Verification of FAM20C expression and inactivation. (A) Genomic DNA was extracted from the tails of mice of each genotype and genotyping was performed with specific primers for the floxed Fam $20 \mathrm{c}$ allele, the recombined Fam $20 \mathrm{c}$ allele and the $\mathrm{Mmtv}$ - Cre allele. (B) Immunofluorescence assay of FAM20C in the SMG. The SMG from control littermates exhibited strong staining. FAM20C was expressed in the cytoplasm of the ID, SD and ED cells (long arrows) and the GCT cells (short arrows); in contrast, the cells from cKO mice did not stain. (C) Immunohistochemistry of FAM20C in the SMG, PG and SLG. In the SMG of control mice, FAM20C was expressed in the cytoplasm of the ID, SD and ED cells (long arrows) and the GCT cells (short arrows). In the PG and SLG of control mice, the immunostaining signal for FAM20C was also observed in the ductal cells, whereas the cKO mice did not stain. For images of Fam $20 c^{f f f}$ or Fam $20 c^{f f f}$; Mmtv-cre mice, the second panel presents magnified images of the outlined areas from the corresponding panel. Fam $20 \mathrm{C}$, family with sequence similarity 20-member C; PG, parotid gland; SLG, sublingual gland; SMG, submandibular gland; GCT, granular convoluted tubule; ID, intercalated duct; SD, striated duct; ED, excretory duct; cKO, Fam20 fff; Mmtv-Cre conditional knockout.

male mice was composed of $\sim 40 \%$ acinar areas; however, the acinar cross-sectional area in the SMG of male cKO mice covered $20 \%$ of the gland. The SMG of normal female mice was composed of $\sim 80 \%$ acinar areas; however, the acinar cross-sectional area in the SMG of female cKO mice covered $\sim 60 \%$ of the gland (Fig. 2A and B). In contrast, ductal structures were more prominent and ductal cross-sectional areas were increased in the SMGs of male and female cKO mice. The SMG of normal male mice was composed of $\sim 30 \%$ duct areas; however, the ductal cross-sectional area in the SMG of male cKO mice covered $\sim 85 \%$ of the gland. The SMG of normal female mice was composed of $\sim 20 \%$ duct areas; however, the ductal cross-sectional area in the SMG of female cKO mice covered $\sim 40 \%$ of the gland (Fig. $2 \mathrm{~A}$ and C). In addition to the alterations in the ratio of ductal cells to acinar cells, the diameter of the GCTs became markedly larger and the cells were swollen with acidophilic secretion products in the $\mathrm{SMG}$ of cKO mice. The testosterone levels in the serum were examined to demonstrate that these morphological alterations could not be attributed to androgen changes. There were no significant alterations in serum testosterone levels between the cKO and control mice, indicating that the expanded GCTs are not associated with altered androgens (Fig. 2D).

There was also increased mesenchymal tissue present within the mutant PG, but the density of the ducts did not change appreciably (Fig. 3A). While the SMG exhibited apparent morphological altertions in the cKO mice, the SLG was histologically normal (Fig. 3A). PAS staining was used to observe whether FAM20C affects mucin synthesis in the salivary glands. Mucin production by the SLG and PG was not markedly different between the $\mathrm{cKO}$ and control mice (Fig. 3B).

To further confirm the morphological alterations in the $\mathrm{cKO}$ mice, the protein expression of several functional markers of acinar cells and duct cells in the salivary tissues was examined. To prove that acinar differentiation was reduced in the mutant SMG, immunohistochemical staining 
A
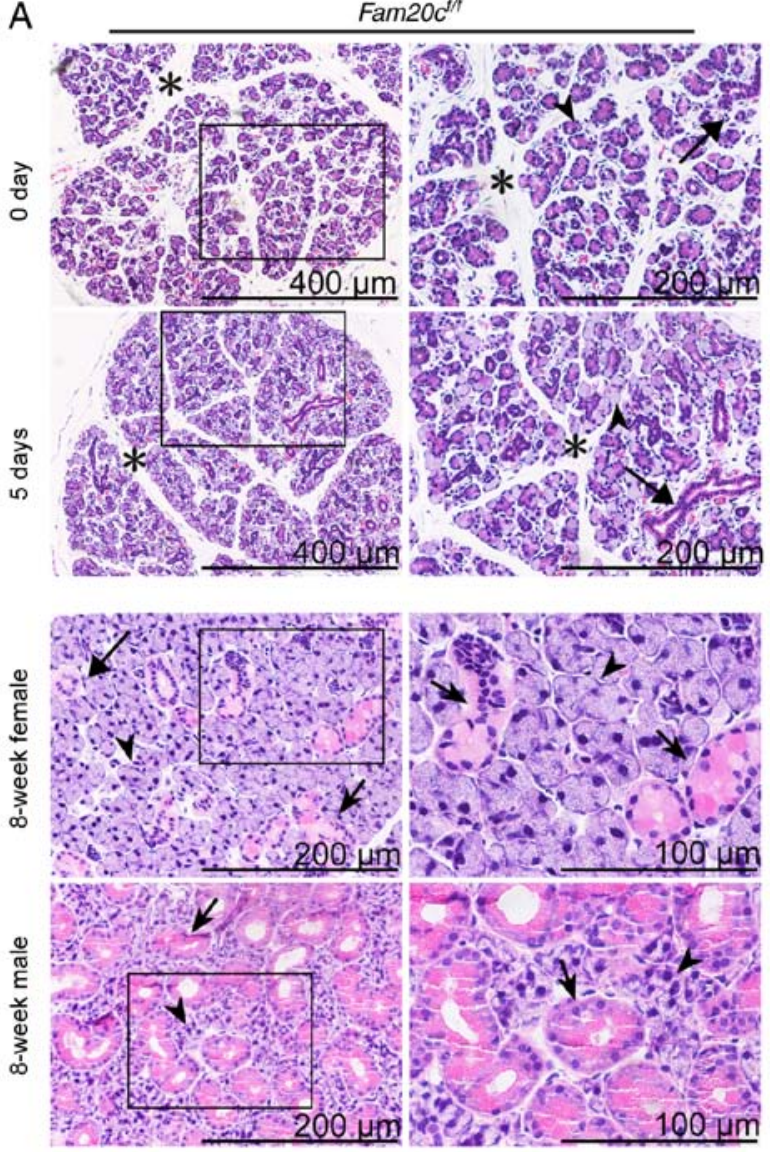

B

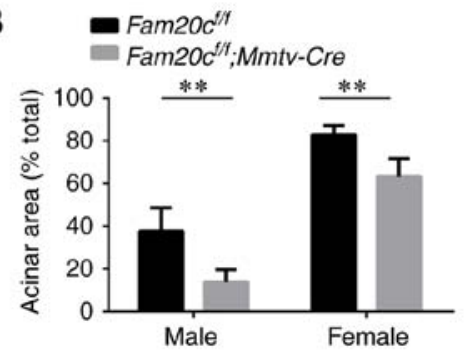

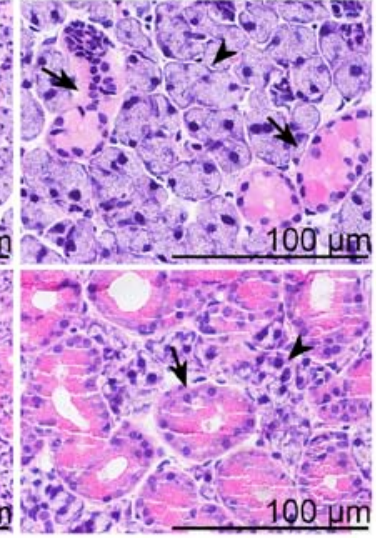

C

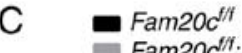

Fam2OCt; Mmtv-Cre

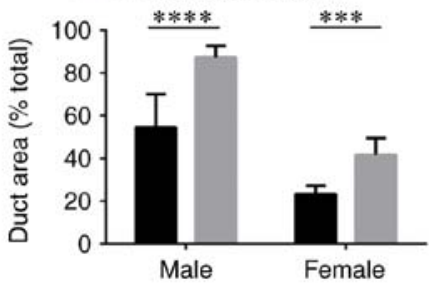

Fam20c $c^{f / 7} ; M m t v-C r e$
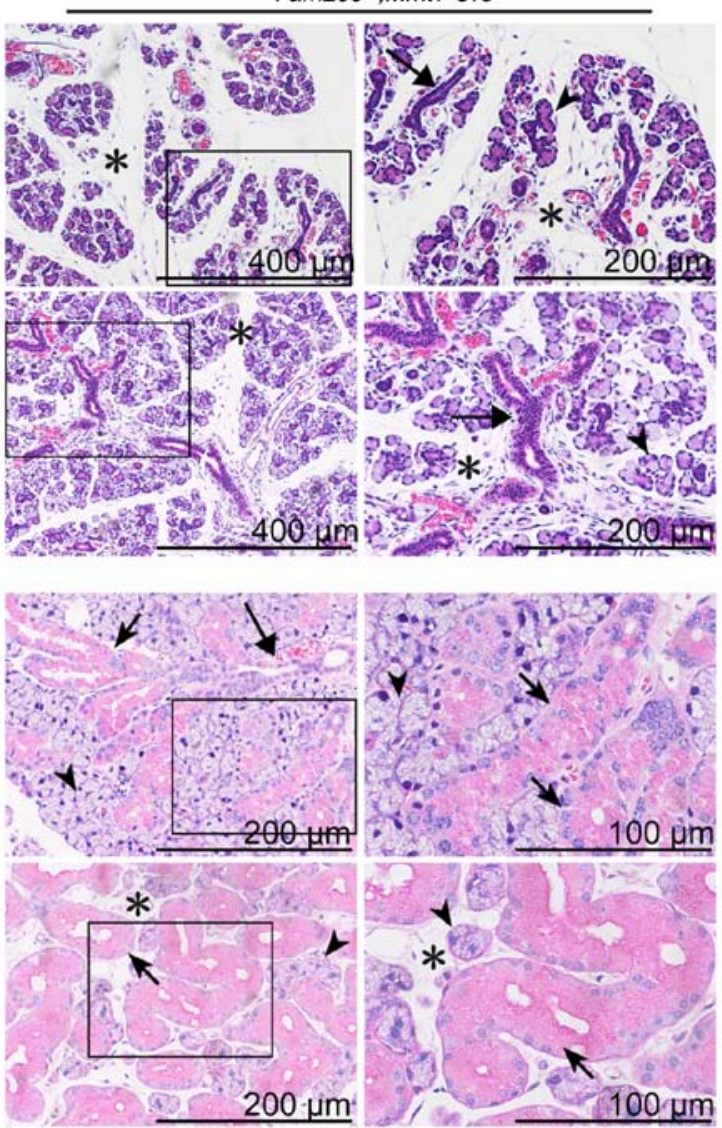

D
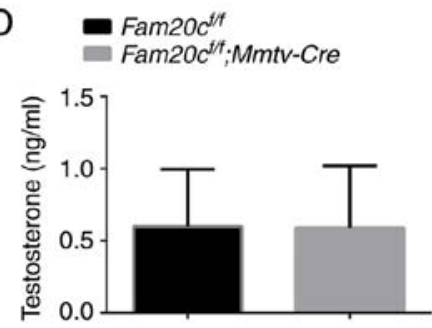

Figure 2. Morphological and structural alterations of the SMG in cKO mice. (A) Salivary glands were collected from six male or female mice at postnatal day 0 , postnatal day 5 or postnatal week 8 for hematoxylin and eosin studies ( $\mathrm{n}=5$ in each group). At postnatal days 0 and 5 , the ducts (long arrows) were more pronounced in the SMG of cKO mice. At postnatal week 8, the ratio of the ductal cross-sectional area was increased significantly (granular convoluted tubule cells: Short arrows) and the mesenchyme was increased (asterisks) in the SMG of the male and female cKO mice. The acinar cells (arrowheads) appeared normal. (B) Quantitative evaluation of the SMG acinar cross-sectional areas. ${ }^{* *} \mathrm{P}<0.01$. (C) Quantitative evaluation of the SMG duct cross-sectional areas male, ${ }^{* * * *} \mathrm{P}<0.0001$ and female, ${ }^{* * *} \mathrm{P}<0.001$. (D) ELISA of serum testosterone. The serum testosterone level was unchanged between cKO and control mice. For images of Fam20 $c^{f f f}$ or Fam20c fff; Mmtv-cre mice, the second panel presents magnified images of the outlined areas from the corresponding panel. SMG, submandibular gland; cKO, Fam20 ${ }^{\text {fff }}$; Mmtv-Cre conditional knockout.

was performed for aquaporin 5 (AQP5), a functional marker of acinar cells. In the SMG of the control mice, AQP5 was expressed in the apical pole of acinar cells and the localization of this expression was normal in the mutant SMG (Fig. 4A). The protein expression of AQP5 was significantly decreased due to the reduced number of acinar cells in cKO mice ( $\mathrm{P}<0.001$; Fig. 4A and B). Cytokeratin 7 (KRT7) is a major marker of ductal cells. The expression of KRT7 was examined to assess the differentiation of ducts. In the SMG of the control mice and cKO mice, KRT7 was expressed in the membrane and cytoplasmic of GCT cells (Fig. 4A). In accordance with the increased ducts in cKO mice, the expression of KRT7 were significantly increased in the SMG of cKO mice $(\mathrm{P}<0.001$; Fig. $4 \mathrm{~A}$ and $\mathrm{C})$.
Fam20c deficiency resulted in defective GCT maturation. Nerve growth factor ( $\beta-\mathrm{NGF}$ ) is a highly specific marker of GCT cells. The expression of $\beta$-NGF was examined to assess the development of GCTs. In the Fam $20 c^{\text {flf }}$ mice, high-level expression of $\beta$-NGF was identified in the cytoplasm of GCT cells (Fig. 4A). However, the expression of $\beta$-NGF was noticeably reduced in cKO mice (Fig. 4A and D).

Amylase is another highly specific marker of GCT cells. The expression of $\alpha$-amylase (SAA) was examined in the SMG to assess the secretion function of GCT cells. The expression of SAA was noticeably reduced in the salivary gland tissues of cKO mice compared to that in the normal control mice. Representative bands, and histograms of the relative protein expression level are displayed in Fig. 4E and F. 
A

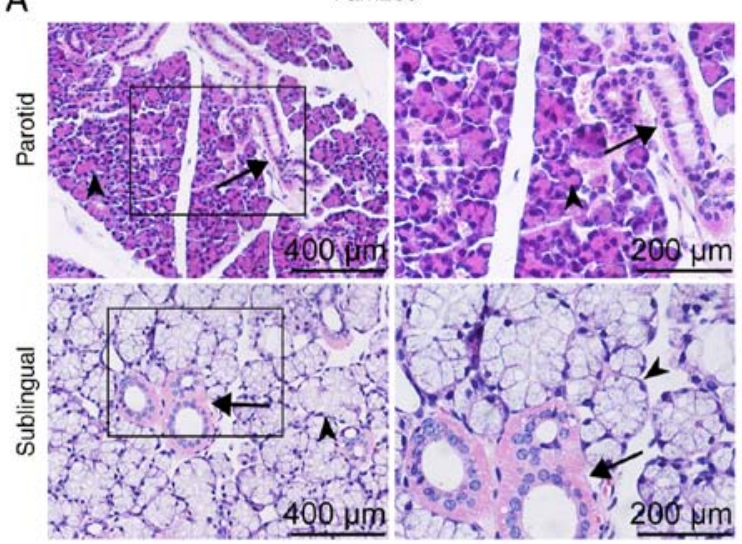

Fam20c $c^{t / f}$
B
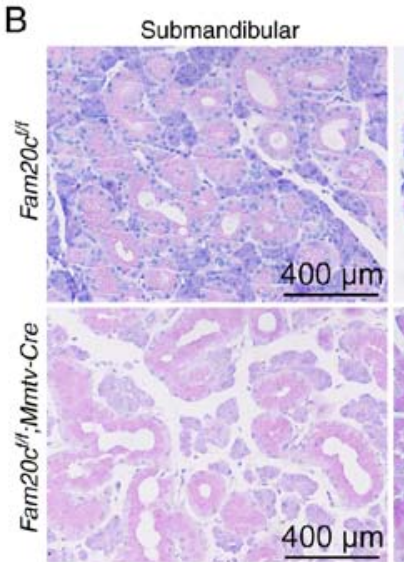

Parotid
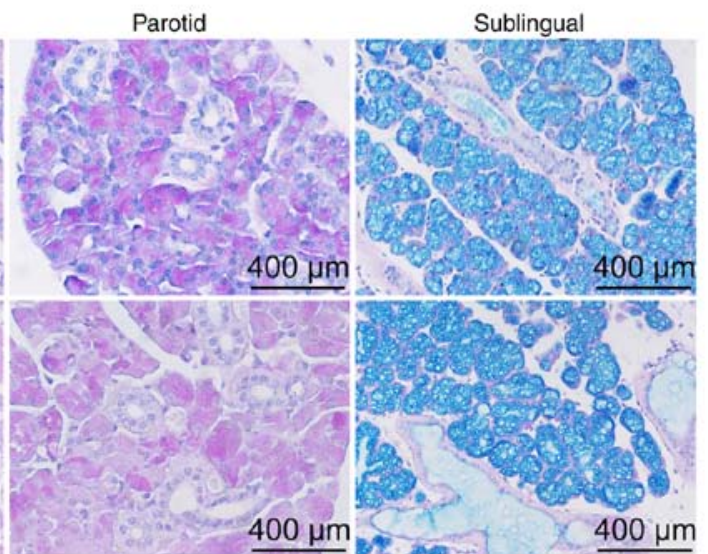

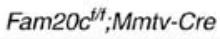

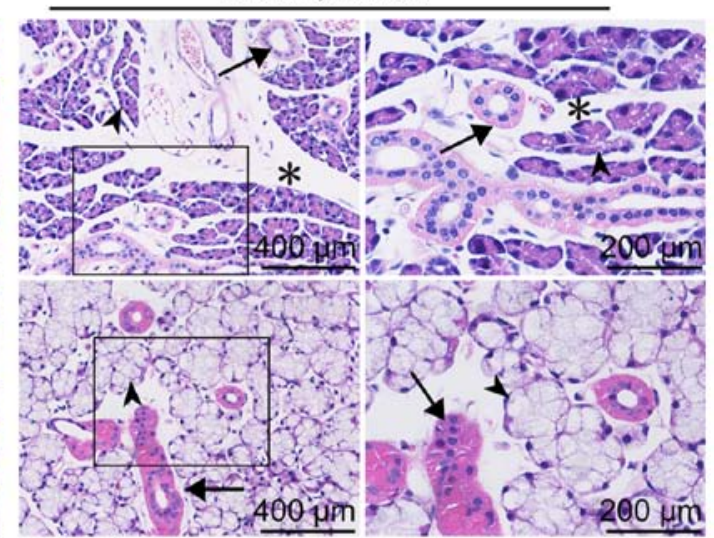

Figure 3. PG/SLG morphological and structural alterations in cKO mice. (A) Hematoxylin and eosin staining of the PG and SLG. There was more mesenchymal tissue (indicated by asterisks) present within the mutant PG. The number of ducts (arrows) and acinar cells (arrowheads) did not change substantially. (B) Periodic Acid-Schiff staining of the SMG, PG and SLG. The production of mucin by the SMG did not change appreciably between the cKO and control mice. Fam20C, family with sequence similarity 20-member C; PG, parotid gland; SLG, sublingual gland; SMG, submandibular gland; cKO, Fam20 ${ }^{f f f}$; Mmtv-Cre conditional knockout.
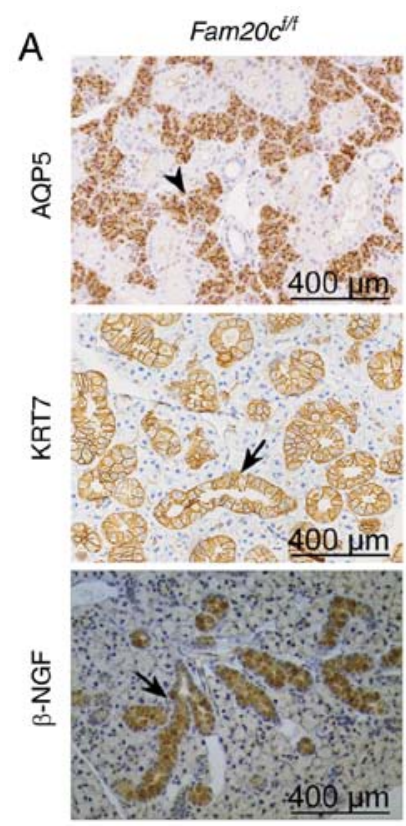

Fam20 $\mathrm{C}^{\mathrm{ff}}:$ Mmtv-Cre
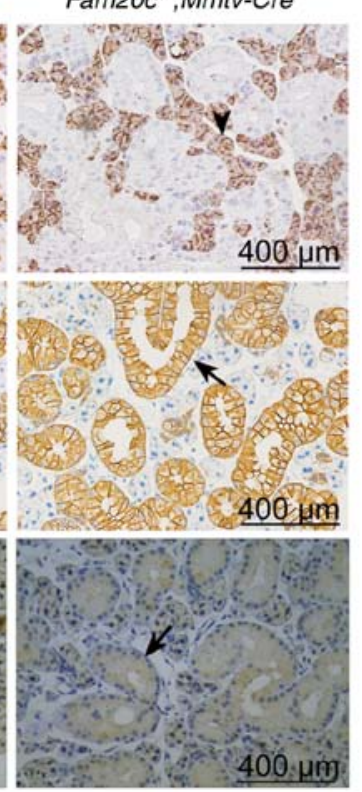

B

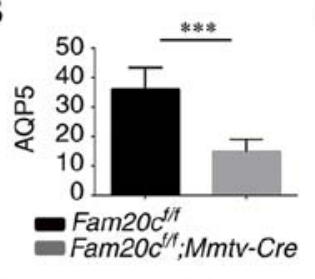

D $200, \stackrel{* \text { *** }}{-}$

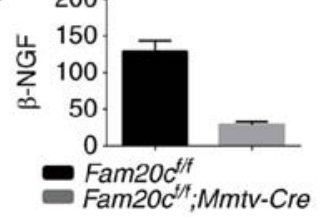

$\mathrm{E}$

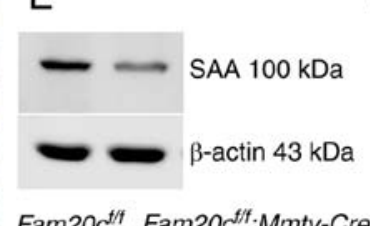

C

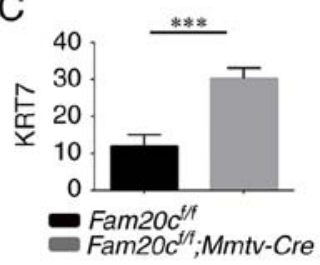

$\mathrm{F}$

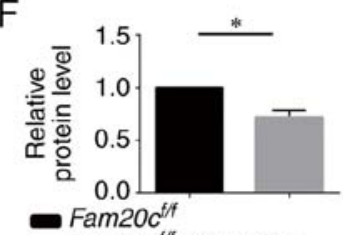

Figure 4. Expression of AQP5, KER7, $\beta$-NGF and SAA in the SMG. (A) Immunohistochemistry of AQP5, KER7 and $\beta$-NGF (duct cells: Arrows; acinar cells: Arrowheads). Semiquantitative immunohistochemical analysis of (B) AQP5, (C) KER7 and (D) $\beta$-NGF. In cKO mice, the expression of AQP5 and $\beta$-NGF was decreased significantly compared with the control mice. ${ }^{* * *} \mathrm{P}<0.001$. The expression of KER7 in cKO mice increased compared with the control mice. ${ }^{* * * *} \mathrm{P}<0.001$. (E) The level of SAA protein was analyzed by western blotting. The expression of SAA was decreased in cKO mice compared with control mice. (F) Densitometry analysis of the western blots is presented. ${ }^{~} \mathrm{P}<0.05$. Error bars represent the standard deviation ( $\mathrm{n}=3$ ). SAA, $\alpha$-amylase; AQP5, aquaporin 5 , KER7, cytokeratin 7; $\beta$-NGF, $\beta$ nerve growth factor; cKO, Fam $20 c^{f f} ;$ Mmtv-Cre conditional knockout. 

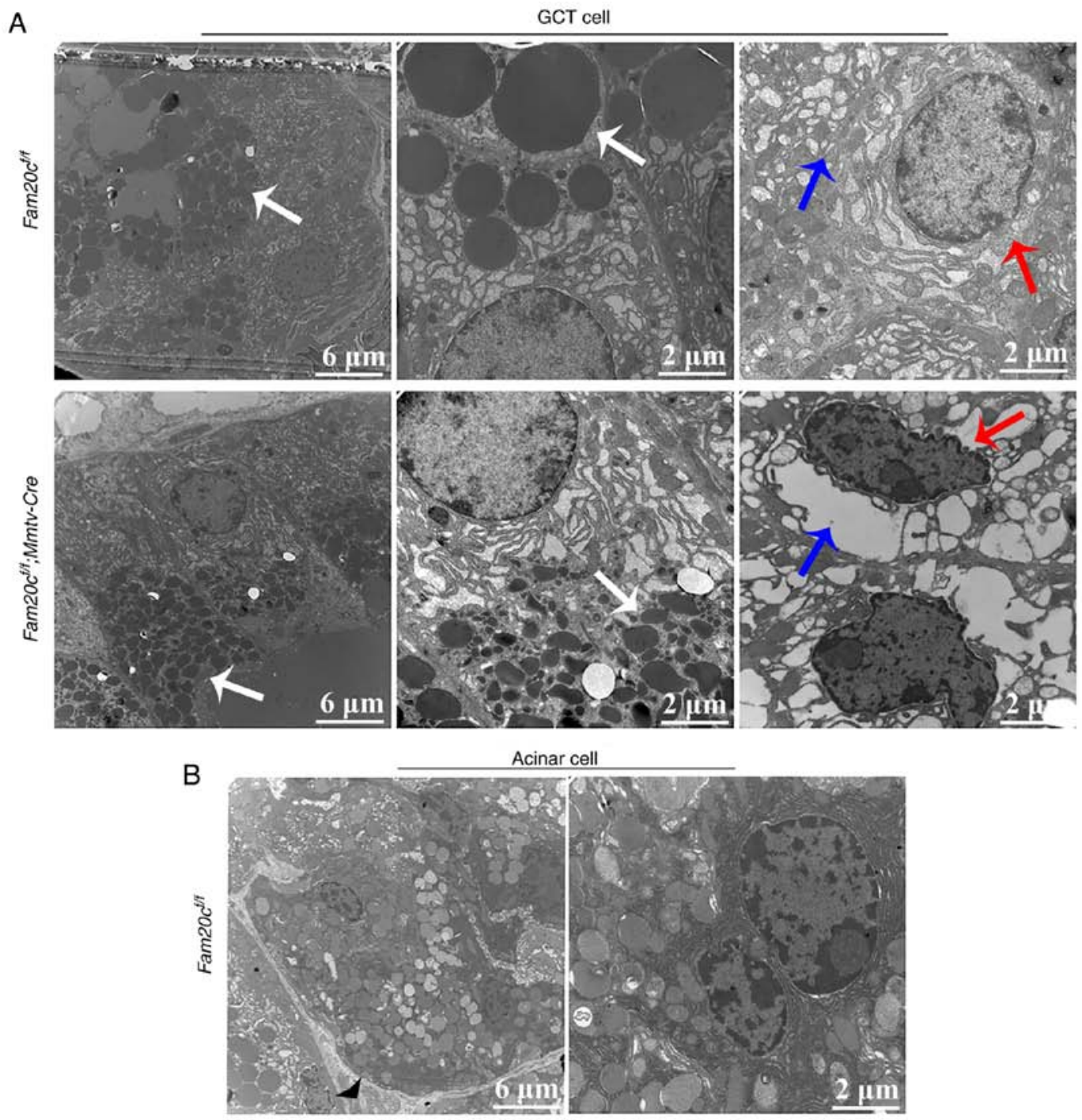

Acinar cell

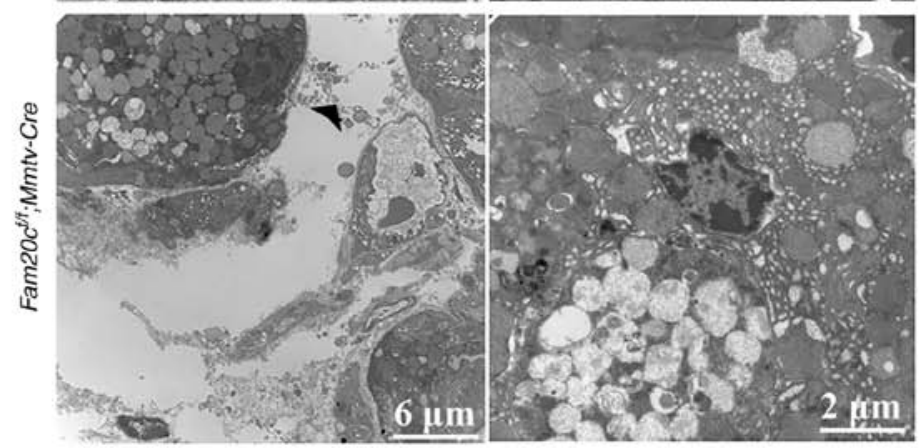

Figure 5. Conditional knockout of Fam20c causes defective maturation of the GCTs. (A) TEM images of GCT cells from each mouse genotype. The white arrows indicate secretory granules, the red arrows indicate the cell nucleus and the blue arrows indicate the endoplasmic reticulum. In GCT cells from control mice, the apical region was filled with rounded, uniformly dense secretory granules (white arrows). In GCT cells from cKO mice, the morphology of the secretory granules appeared aberrant (white arrows). Certain GCT cells from cKO mice demonstrated nuclear pyknosis (red arrows) and hollowing of the rough endoplasmic reticulum (blue arrows). (B) TEM images of acini from each mouse genotype. In cKO mice, the cell gap was wider than that in the control mice (arrowheads). TEM, transmission electron microscope; GCT, granular convoluted tubule; cKO, Fam20c fff; Mmtv-Cre conditional knockout; Fam20C, family with sequence similarity 20 -member C.

To further determine whether Fam20c deficiency affected the secretory function of GCT cells, the cell structure of the GCT cells was examined by transmission electron microscopy (TEM). The apical region of the GCT cells was filled with rounded and uniformly dense secretory granules. The TEM images demonstrated that very small secretory granules with aberrant morphology accumulated in the GCT cells of $\mathrm{cKO}$ mice; in comparison, the granules in the GCT cells of the control mice were of normal size, indicating that the GCT cells were at an immature stage of development in the cKO mice (Fig. 5A). Additionally, in the cKO mice, certain GCT cells appeared to have entered the apoptotic process, as reflected by the presence of endoplasmic reticulum expansion and nuclear condensation. In accordance with these morphological alterations, the 
A

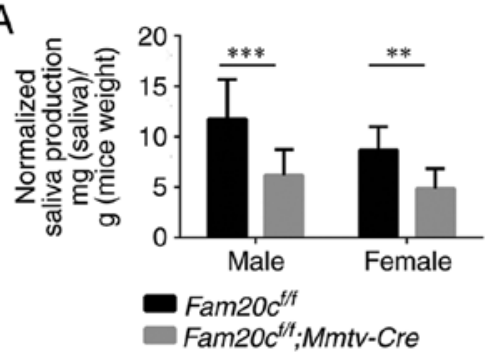

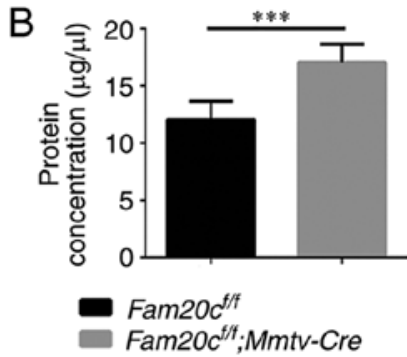
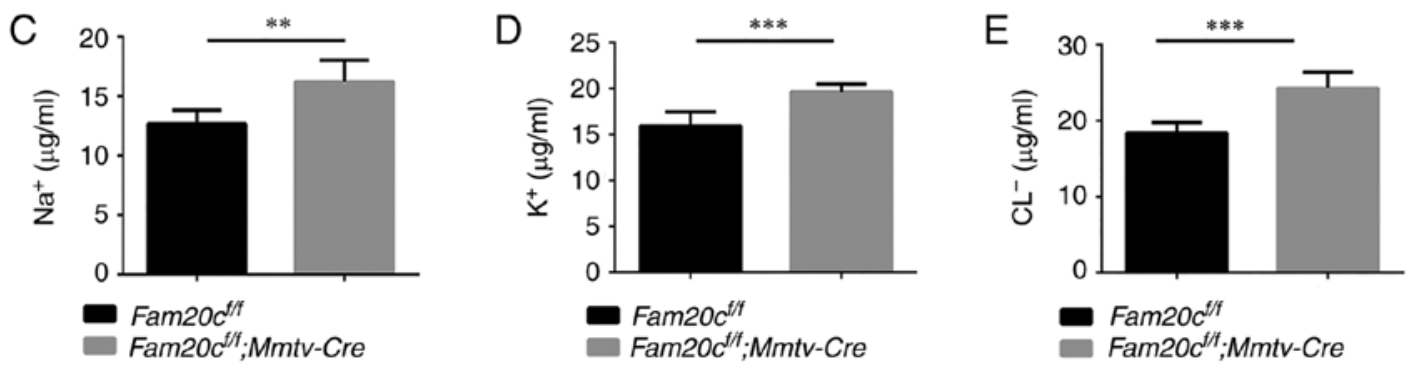

Figure 6. The effects of FAM20C on salivary parameters. (A) The flow rate of saliva. The volume of saliva obtained from male $\left.{ }^{* * *} \mathrm{P}<0.001\right)$ and female $\mathrm{cKO}$ mice ( $\left.{ }^{* *} \mathrm{P}<0.01\right)$ was significantly lower than that obtained from control mice. (B) The total protein concentration of the saliva. The total protein concentration was increased in cKO mice ${ }^{* * * *} \mathrm{P}<0.001$. The (C) Na+ , (D) $\mathrm{Cl}^{-}$and (E) $\mathrm{K}^{+}$ion concentrations in the saliva. The $\mathrm{Na}^{+}, \mathrm{Cl}^{-}$and $\mathrm{K}^{+}$concentrations were significantly increased in saliva from cKO mice compared with saliva from control mice ${ }^{* *} \mathrm{P}<0.01$. cKO, Fam20 ${ }^{f f} ;$ Mmtv-Cre conditional knockou; Fam20C, family with sequence similarity 20 -member $\mathrm{C}$.

mesenchyme was increased in the SMG of cKO mice compared with that in the normal control mice (Fig. 5B).

Saliva from Fam20c-deficient mice exhibits an abnormal flow rate and composition. To determine whether the morphological alterations observed in the $\mathrm{cKO}$ mice resulted in dysfunction of the salivary gland, the flow rate and electrolyte composition of saliva were measured. Saliva is mainly produced in the acini and the electrolytes secreted by the acini are resorbed in the duct (35). In accordance with the morphological changes that indicated the presence of fewer acinar cells, the volume of saliva obtained from the male and female cKO mice was significantly decreased compared with that obtained from the control mice $(\mathrm{P}<0.01$; Fig. $6 \mathrm{~A})$. In addition, the concentration of total protein in the saliva from cKO mice was significantly increased compared with in the saliva from the control mice $(\mathrm{P}<0.001$; Fig. $6 \mathrm{~B})$. Analyses of the ion concentrations in the saliva demonstrated that the $\mathrm{Na}^{+}, \mathrm{Cl}^{-}$and $\mathrm{K}^{+}$concentrations in the saliva were significantly increased in the $\mathrm{cKO}$ mice compared with in the control mice $(\mathrm{P}<0.01$; Fig. 6C-E). These results indicated that knockout of Fam 20c influenced the secretory function of the salivary glands.

Conditional knockout of Fam20c leads to an altered BMP4 distribution pattern and attenuates BMP signaling. As a family of secreted proteins, BMPs, especially BMP4, have a typical $\mathrm{S}-\mathrm{x}-\mathrm{E} / \mathrm{S}$ motif and are predicted to be substrates of FAM20C (16). IHC and WB were performed to determine whether the expression of BMP2, BMP4, and BMP7 and the activity of canonical and noncanonical signaling pathways were altered in the salivary glands of the cKO mice. In Fam 20 cff mice, BMP4 was localized to the cytoplasm of ID, SD and ED cells, particularly GCT cells, and was widely distributed in the ECM in the SMG. However, in cKO mice,
BMP4 accumulated in the GCT cells but was nearly undetectable in the ECM (Fig. 7A). These results demonstrated that the conditional inactivation of Fam $20 \mathrm{c}$ resulted in an altered BMP4 distribution pattern. In the SMG of the normal control and cKO mice, pan-mothers against decapentaplegic homolog 9 (Smad)1/5/9, p-Smad1/5/9, pan-extracellular signal regulated kinase (ERK) and pan-p38 were mainly localized to the cytoplasm of the duct cells, and phosphorylated (p)-Erk and p-p38 was expressed in the nucleus of the duct cells (Fig. 7B and C). In the PG and SLG of the normal control and cKO mice, BMP4 was also localized to the cytoplasm of duct cells, and the expression was downregulated in the cKO mice (Fig. 8A and B). The expression and location of BMP signaling pathway members in the $\mathrm{PG}$ and SLG were the same as in the SMG (Fig. 8C-F). In addition, WB revealed that Fam20c deficiency significantly increased BMP2 and BMP7 expression and decreased BMP4 expression $(\mathrm{P}<0.05$; Fig. 9A). Notably, it was observed that although the transcription of Bmp 4 did not change, the transcript levels of Bmp2 and Bmp7 were significantly increased $(\mathrm{P}<0.05$; Fig. 9B), which implied that phosphorylation may be important for the activity of BMP ligands. The results of WB were consistent with IHC. The expression of both $\mathrm{p}-\mathrm{Smad} 1 / 5 / 9$ and pan-Smad1/5/9 significantly decreased in cKO mice $(\mathrm{P}<0.05)$, but the ratio of $\mathrm{p}-\mathrm{Smad} 1 / 5 / 9$ to $\mathrm{pan}-\mathrm{Smad1} / 5 / 9 \mathrm{did}$ not alter significantly between Fam $20 \mathrm{c}^{\mathrm{flf}}$ mice and Fam $20 \mathrm{c}^{\mathrm{ff} f}$; Mmtv-Cre mice (Fig. 9C). The expression of pan-ERK was not different between the control mice and cKO mice, but the $\mathrm{p}$-Erk/pan-Erk ratio was significantly decreased in the cKO mice due to the reduction in $\mathrm{p}$-Erk $(\mathrm{P}<0.05$; Fig. 9D). Despite the downregulation of both pan-p38 and p-p38, the p-p38/pan-p38 ratio increased markedly in the $\mathrm{cKO}$ mice (Fig. 9E). These results implied that Fam20c deficiency altered the activity of the canonical and noncanonical BMP signaling pathways. 
A $\quad$ BMP4

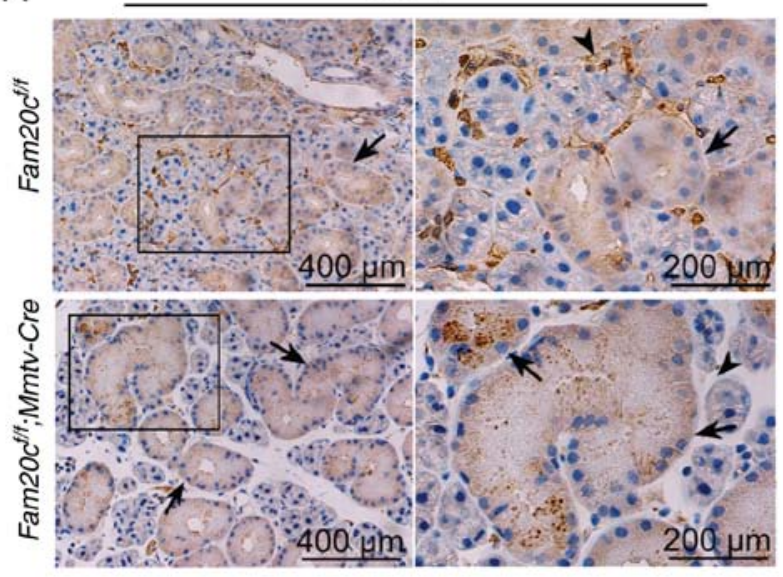

B
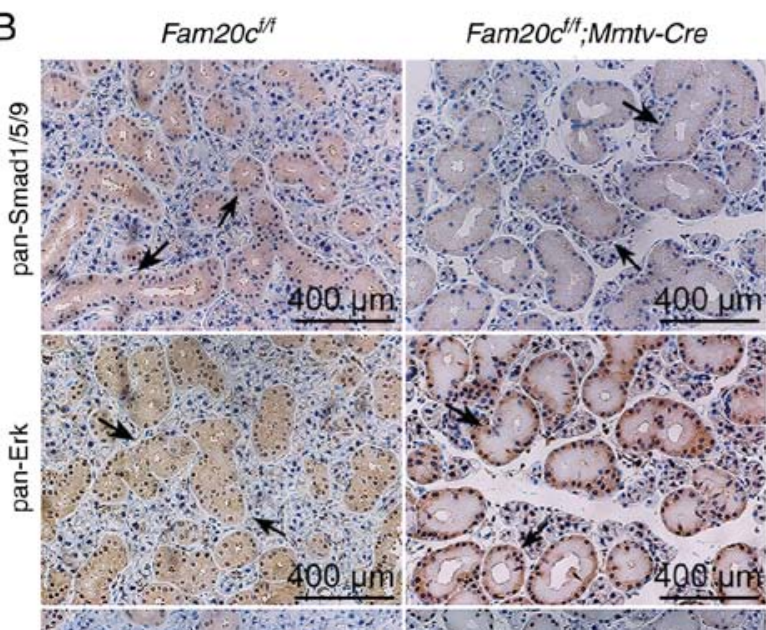

C Fam2Octir Fam20 ${ }^{\prime \prime \prime} ;$ Mmtv-Cre
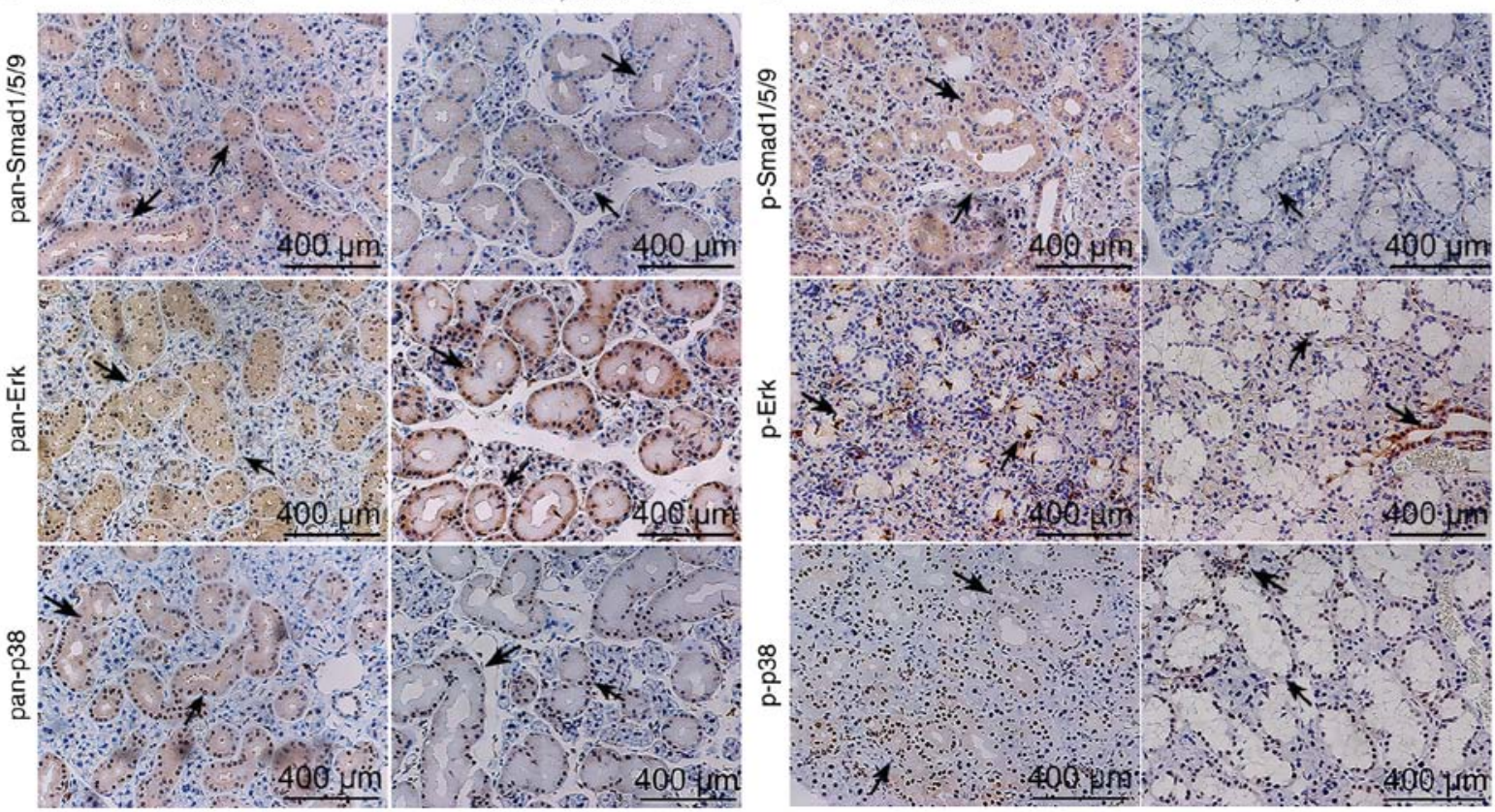

Figure 7. Conditional knockout of Fam20c leads to an altered BMP4 distribution pattern and altered BMP expression in the SMG. (A) IHC of BMP4 in the SMG. In control mice, BMP4 was localized in the cytoplasm of ducts cells (black arrows) and ECM (arrowheads). In the cKO mice, BMP4 was restricted to ducts (black arrows). For images of Fam20 fff or Fam20 fff; Mmtv-cre mice, the second panel presents magnified images of the outlined areas from the corresponding panel. IHC of BMP signaling pathways components in the SMG. IHC reaction to (B) pan-Smad1/5/9, (C) p-Smad1/5/9, pan-ERK and pan-p38 were detected in the cytoplasm of duct cells (black arrows) while the signals against p-Erk and p-p38 were observed in the nucleus (red arrows). IHC, immunohistochemistry; BMP, bone morphorgenic protein; Smad, mothers against decapentaplegic homolog 9; p-, phosphorylated; ERK, extracellular signal regulated kinase; Fam20C, cKO, Fam20c $c^{f f}$; Mmtv-Cre conditional knockout; family with sequence similarity 20 -member C.

\section{Discussion}

FAM20C is expressed in multiple tissues, including mineralized and nonmineralized tissues and bodily fluids $(21,22,33)$. FAM20C can phosphorylate $>100$ secreted proteins; the broad substrate spectrum and ubiquitous distribution of FAM20C indicate that in addition to its role in biomineralization, this kinase may serve roles in a number of other biological functions (16). Therefore, it is necessary to eliminate Fam $20 \mathrm{c}$ specifically in the salivary glands to investigate the biological effects of this enzyme on the development and function of the salivary gland. In the present study, $\mathrm{Mmtv}$-Cre mice were used, in which Cre activity was restricted to the ductal cells of the salivary gland at an early embryonic stage (29), to prevent the expression of Fam20c in the salivary gland.
In this study, the distribution of FAM20C was assessed in the salivary glands and demonstrated that FAM20C serves an important role in the formation and maturation of the salivary gland ducts. Phenotypic analysis by histological staining demonstrated that more mesenchymal tissue and smaller lobules were present within the mutant salivary glands, and the proportion of duct to acinar cells was altered by the inactivation of Fam20c at 0,5 days and 8 weeks following birth. This result is highly suggestive of a branching defect during embryogenesis that leads to the formation of fewer epithelial end buds and ultimately fewer secretory acini. The induction of duct differentiation and inhibition of acinar differentiation were further supported by the expression alterations in AQP5 and KRT7. AQP5 is a water channel protein, which serves a major role in regulating the saliva fluid secretion. The 
A

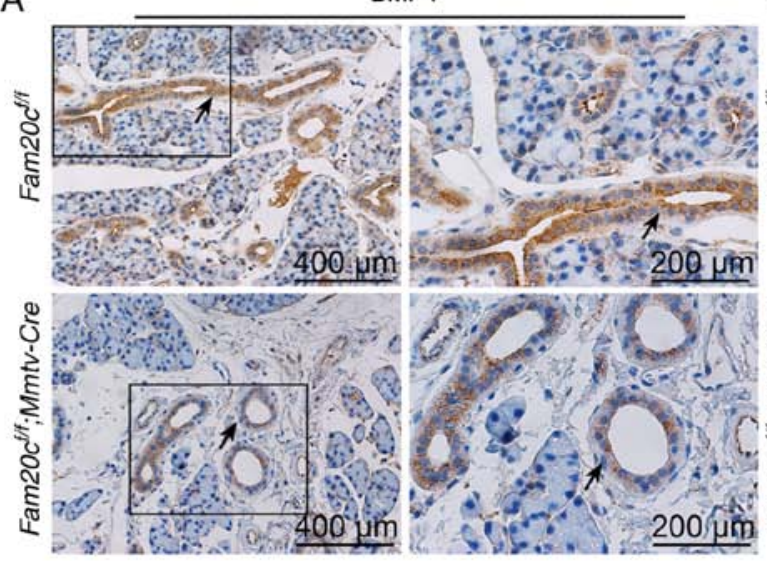

C
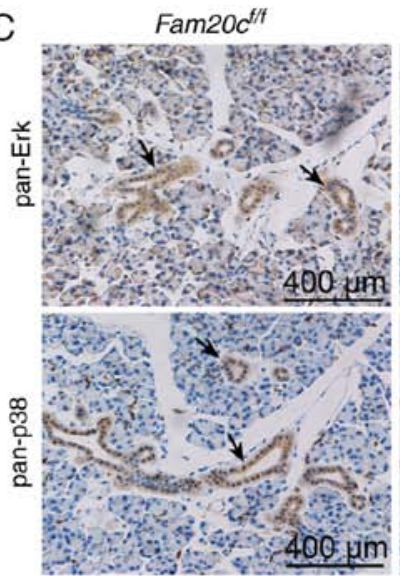

E

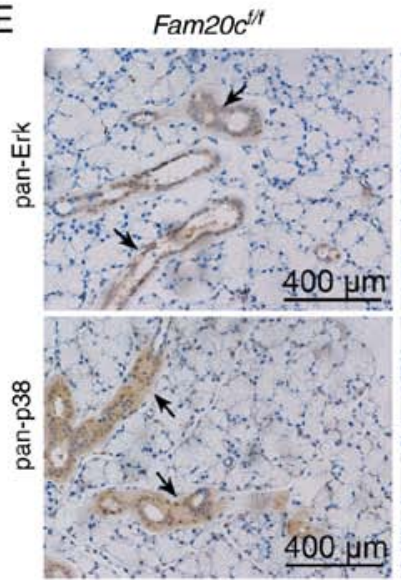

Fam20 $c^{\text {ft; }}$;Mmtv-Cre

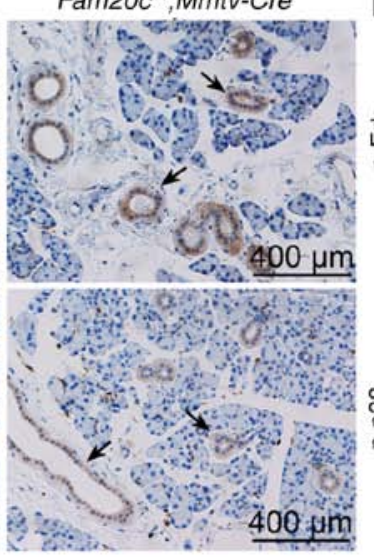

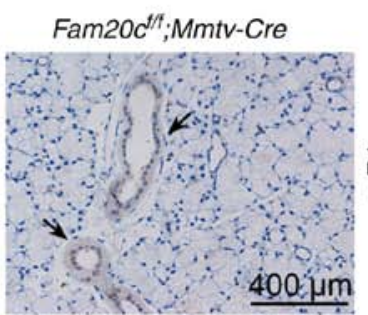

B

BMP4
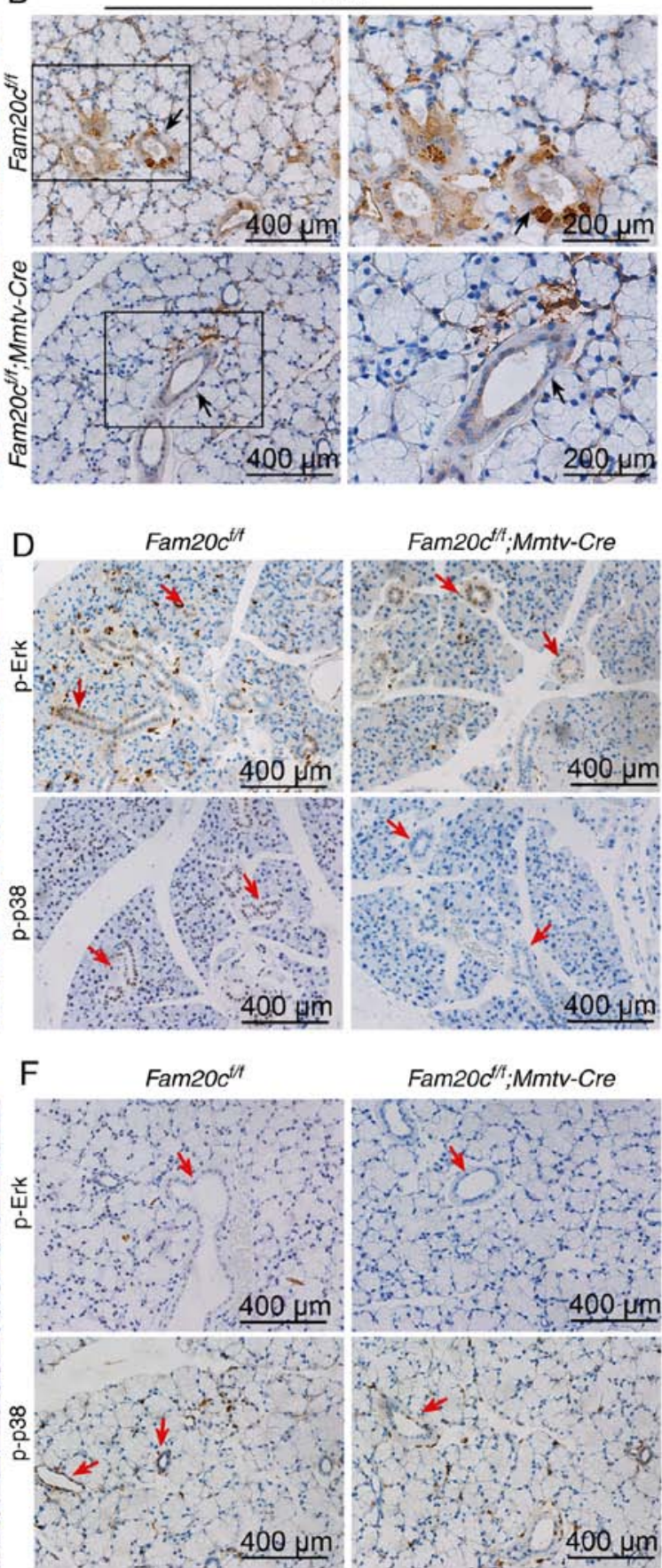

Figure 8. Conditional knockout of Fam20c leads to alterations in the distribution pattern of BMP4 and the expression of BMP signaling pathway components in the PG and SLG IHC of BMP4 in the (A) PG and the (B) SLG. In control mice, BMP4 was localized to the cytoplasm of duct cells (black arrows). For images of Fam $20 c^{f f f}$ or Fam 20c fff; Mmtv-cre mice, the second panel exhibits magnified images of the outlined areas from the corresponding panel. IHC of BMP signaling pathways in the PG and the SLG. (C) IHC of pan-ERK and pan-p38 in the PG. (D) IHC of p-ERK and p-p38 in the PG. (E) IHC of pan-ERK and pan-p38 in the SLG. (F) IHC of p-ERK and p-p38 in the SLG. IHC reaction to pan-ERK and pan-p38 were detected to the cytoplasm of duct cells (black arrows), however the p-Erk and p-p38 were observed in the PG (red arrows) but not in the SLG (red arrows). IHC, immunohistochemistry; BMP, bone morphorgenic protein; p-, phosphorylated; ERK, extracellular signal regulated kinase; PG, parotid gland; SLG, sublingual gland; Fam20C, family with sequence similarity 20-member C.

production level of AQP5 indicates defective acinar cell function $(35,36)$. The reduced expression of AQP5 in cKO mice was the result of inhibition of acinar differentiation. KRT7 is expressed strongly in the ducts of the SMG and a number of other glandular tissues from E14 (37,38). Fam20c deficiency in salivary glands increased the expression of KRT7 indicated that FAM20C promoted induction of duct differentiation. Theoretically, the development of GCT cells depends on androgen signaling and the GCTs are much larger in the SMG in males (34). However, in the present study, although the GCT duct cells were larger in the cKO mice, the concentration of serum testosterone was not different between the control and cKO mice. In male and female adult cKO mice, along with the morphological alterations of GCTs, the cross-sectional areas of the duct cells were increased, without sex-associated differences. Therefore, the morphological alterations were 

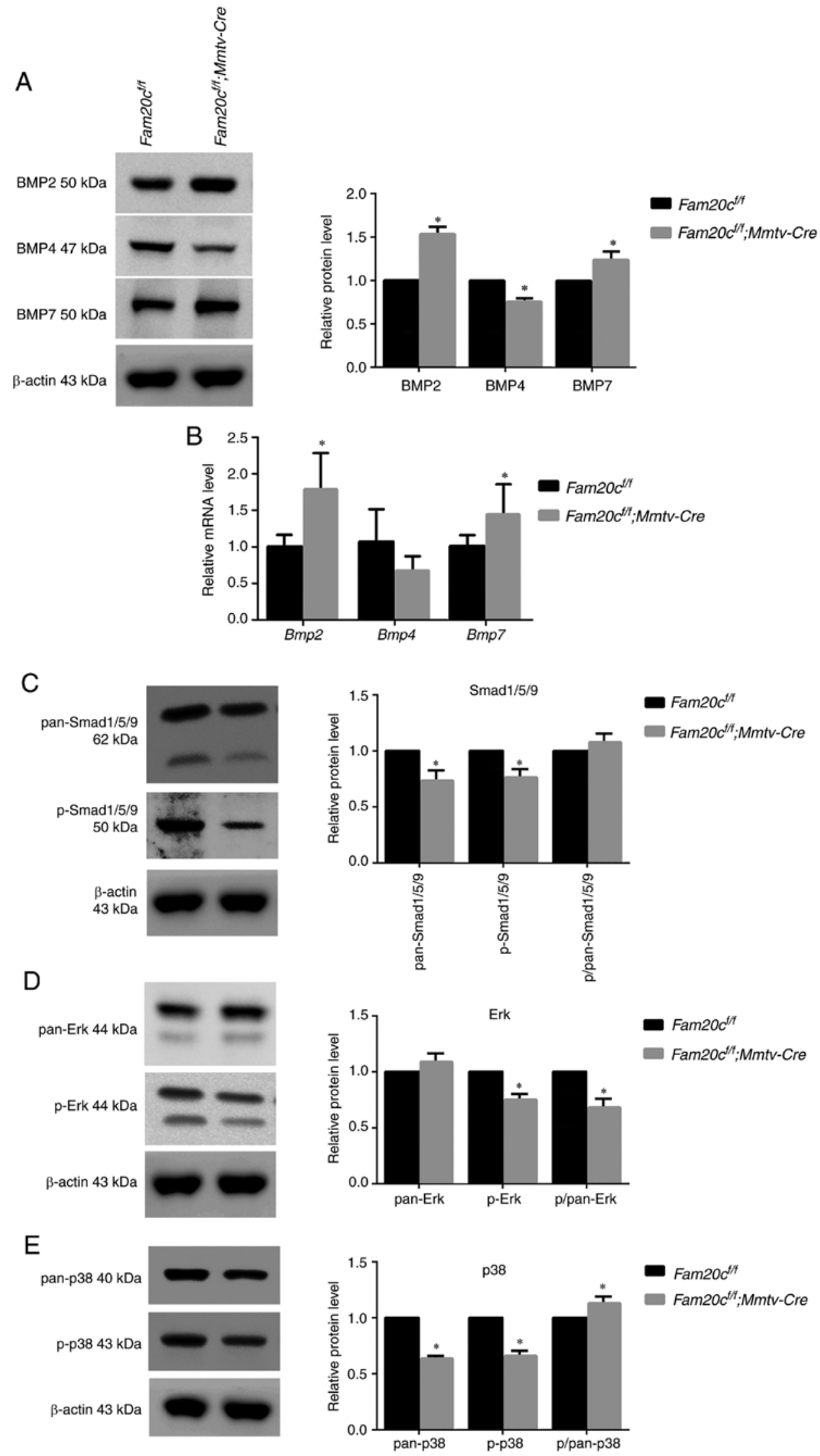

Figure 9. The canonical and noncanonical BMP signaling pathways are attenuated in the SMG of cKO mice. (A) Canonical and noncanonical BMP signaling pathways components were examined by western blotting with antibodies against BMP2, BMP4 and BMP7. (B) Comparison of the relative mRNA expression levels of Bmp2, Bmp 4 and Bmp7 between normal control mice and cKO mice. " $\mathrm{P}<0.05$. (C) Canonical and noncanonical BMP signaling pathways components were examined by western blotting, with antibodies against pan-Smad1/5/9 and p-Smad1/5/9, with antibodies against (D) pan-Erk and (E) p-Erk, and with antibodies against pan-p38 and p-p38. $\beta$-actin was used as the internal control. ${ }^{*} \mathrm{P}<0.05$ vs. the Fam $20 c^{f f f}$ mice and the error bars represent the standard deviation $(\mathrm{n}=3)$. BMP, bone morphogenic protein; Smad, mothers against decapentaplegic homolog 9; $\mathrm{p}-$, phosphorylated; ERK, extracellular signal regulated kinase; cKO, Fam $20 c^{f f f}$; Mmtv-Cre conditional knockout. 
not attributed to androgen signaling but rather to the role of FAM20C.

Although FAM20C was expressed only in the ducts of salivary glands in adults, knockout of FAM20C promoted ductal differentiation and restricted acinar differentiation. In the salivary glands, morphological differentiation of most acinar and ductal cells occurred at E17 and continued following birth until puberty (39-41). The expression of $M m t v-C r e$ can already be observed prior to E11.5 and is clearly visible at E13.5 and E15.5 (27). The mRNA and protein of Fam20c were detected in the teeth and at ossification sites in the head at E14.5 and were also expressed in the cerebral cortex and cranial nerve ganglia in E15.5 and E16.5 embryos (21). All these previous studies provided clues that FAM20C may modulate salivary acinar and ductal differentiation during early embryonic development. Therefore, although FAM20C was expressed only in the ducts following birth, the proportion of duct cells to acinar cells was affected by the knockout of FAM20C in the salivary gland. The PG and SLG were histologically normal in the cKO mice, implying that the SMG may simply be more sensitive to Fam20c deficiency during morphogenesis than the PG and SLG.

GCT epithelial cells have numerous secretory granules containing various bioactive peptides, including $\beta$-NGF (42), whose expression level parallels the maturation of GCTs $(34,37,43)$. Amylase is an important digestive enzyme for polysaccharides and it is produced by acinar cells of the PG, serous demilune cells of the SLG, and GCT cells of the male SMG (44-46). Previous studies $(47,48)$ demonstrated that SAA activity in mouse SMG homogenates increased following puberty, paralleling the development of GCT cells, which leads to sex-biased levels in adulthood. In the present study, although the number and cross-sectional area of ducts increased in the Fam 20 -null mice, the expression of $\beta$-NGF and SAA was noticeably reduced suggesting the abnormal function of the GCT duct cells. In addition, TEM revealed the accumulation of very small secretory granules with aberrant morphology in the Fam20c-deficient GCT cells, suggesting that FAM20C may participate in regulating the biogenesis and secretion of secretory granules and may be involved in the highly specific steps of secretory organelle maturation (49), considering that the Golgi participates in the biogenesis of secretory granules (50). FAM20C phosphorylates secretory proteins within the consensus sequence $\mathrm{S}-\mathrm{X}-\mathrm{E} / \mathrm{pS}$, which is present in BMP2, BMP4 and BMP7; therefore, BMPs may be the substrates for FAM20C. In the present study, the loss of Fam20c resulted in the abnormal expression of BMP4; BMP4 was not observed in the mesenchyme. Secreted proteins are stored at high concentrations in dense-core secretory granules, which can be released in response to external signals (51) and are important for the transport of secreted proteins. Whether abnormally expressed BMP4 accumulated in the cytoplasm of GCT cells due to dysregulated transport of the immature secretory granules or to structural alterations in proteins that cannot be phosphorylated is unclear. Therefore, future studies are needed to demonstrate the specific effect of FAM20C on the transport of secretory proteins.

The normal function of salivary glands requires an adequate area of salivary gland acini that function effectively.
The abnormal morphology of the cKO salivary glands, with reduced acinar cell differentiation, was confirmed by the reduced expression of AQP5. However, these acinar cells appeared to be perfectly formed and not atrophic. This finding suggests that the secretory function of acinar cells is normal in the cKO mice, but owing to the smaller number of acinar cells, less saliva is secreted. The alterations in the electrolyte composition of the saliva suggest that the altered physiological function of the ducts may result from ductal immaturity.

Past studies $(6,10,52)$ on the salivary glands focused mostly on branching development and studies on the regulation of the acini to duct ratio were limited. FAM20C is a phosphorylated protein kinase that specifically recognizes $\mathrm{S}-\mathrm{x}-\mathrm{E} / \mathrm{pS}$ motifs. BMPs contain multiple phosphorylated $\mathrm{S}-\mathrm{x}-\mathrm{E} / \mathrm{S}$ motifs, including BMP2 $\left({ }^{46} \mathrm{SDE}^{48},{ }^{117} \mathrm{SLE}^{119}\right.$ and $\left.{ }^{147} \mathrm{SAE}^{149}\right)$, BMP4 $\left({ }^{50} \mathrm{SHE}^{52},{ }^{91} \mathrm{SGE}^{93}\right.$ and $\left.{ }^{155} \mathrm{SAE}^{157}\right)$, and BMP7 $\left({ }^{48} \mathrm{SQE}^{50},{ }^{219} \mathrm{SEE}^{221}\right.$ and $\left.{ }^{248} \mathrm{SVE}^{250}\right)$, implying that FAM20C may phosphorylate BMPs. Analysis of gene expression associated with salivary gland morphogenesis indicated that BMPs serve important roles during embryonic SMG morphogenesis. It was reported that compared with $\mathrm{SMGs}$ from $B m p 7^{7^{++}}$mice, SMGs from $B m p 7^{-1-}$ mice exhibit a disordered mesenchyme and markedly fewer ducts; the effect of BMP4 on the salivary glands is opposite to that of BMP7; BMP4 inhibits the size and number of buds, as well as further branching (9). In the present study, it was demonstrated that FAM20C deficiency altered the protein level and/or distribution of BMP2, BMP4 and BMP7 but did not alter the mRNA level of Bmp4. Furthermore, BMP signaling pathways were attenuated in the salivary gland of cKO mice. FAM20C deficiency resulted in the attenuated phosphorylation of Smad1/5/9, Erk and p38 in the salivary glands, implying that FAM20C positively regulates BMP signaling via the phosphorylation of BMP ligands. Another study from the authors' group (not yet published) demonstrated that the number of salivary gland ducts increased significantly in $\mathrm{Bmp} 2^{f f f} ; \mathrm{Bmp} 4^{f / f} ; \mathrm{K} 14$-Cre mice. The similar morphological changes in the salivary glands from Fam $20 C$ cKO mice and Bmp2;Bmp 4 double-cKO mice indicates that FAM20C may affect the development of salivary glands via the BMP signaling pathway. Future studies are warranted to validate the hypothesis that FAM20C inhibits duct formation by regulating BMP signaling.

In conclusion, the results of the present study demonstrated that FAM20C may be a key regulator of acinar and duct structure and duct maturation; therefore, the results augment existing information about the biological roles of FAM20C, establish a possible link between FAM20C and the transport of secreted proteins and provide a novel avenue for investigating new therapeutic targets for oral diseases including xerostomia.

\section{Acknowledgements}

Not applicable.

\section{Funding}

The present study was supported by the Postgraduate Research Innovation Fund of Harbin Medical University (grant no. YJSCX2017-61HYD), the National Natural Science Foundation of China (grant nos. 81870736, 81801040 
and 81600848), the Special Foundation for Sino-Russian Translational Medicine Research Center of Harbin Medical University (grant nos. CR201412 and CR201504), and the Natural Science Foundation of Heilongjiang Province of China (grant no. H2015103), Science Foundation of the Second Affiliated Hospital of Harbin Medical University (grant no. CX2016-20).

\section{Availability of data and materials}

All data generated or analyzed during this study are included in the published article.

\section{Authors' contributions}

BZ, YL and CQ conceived and designed the experiments. NM, YZ, YX, HY, XX and SG performed the experiments. NM, SM, FL, HM and MY analyzed the data. NM and CQ wrote the paper. All authors read and approved the final manuscript.

\section{Ethics approval and consent to participate}

All animal procedures used in this study were approved by the Institutional Animal Care and Use Committee of Harbin Medical University.

\section{Patient consent for publication}

Not applicable.

\section{Competing interests}

The authors declare that they have no competing interests.

\section{References}

1. Fox PC: Autoimmune diseases and Sjogren's syndrome: An autoimmune exocrinopathy. Ann NY Acad Sci 1098: 15-21, 2007.

2. Shiboski CH, Hodgson TA, Ship JA and Schiødt M: Management of salivary hypofunction during and after radiotherapy. Oral Surg Oral Med Oral Pathol Oral Radiol Endod 103 (Suppl): S66 e61-e19, 2007.

3. Nederfors T: Xerostomia and hyposalivation. Adv Dent Res 14: 48-56, 2000.

4. Napeñas JJ, Brennan MT and Fox PC: Diagnosis and treatment of xerostomia (dry mouth). Odontology 97: 76-83, 2009.

5. Tucker AS: Salivary gland development. Semin Cell Dev Biol 18: 237-244, 2007

6. Patel VN, Rebustini IT and Hoffman MP: Salivary gland branching morphogenesis. Differentiation 74: 349-364, 2006.

7. Harunaga J, Hsu JC and Yamada KM: Dynamics of salivary gland morphogenesis. J Dent Res 90: 1070-1077, 2011.

8. Heine U, Munoz EF, Flanders KC, Ellingsworth LR, Lam HY, Thompson NL, Roberts AB and Sporn MB: Role of transforming growth factor-beta in the development of the mouse embryo. J Cell Biol 105: 2861-2876, 1987.

9. Hoffman MP, Kidder BL, Steinberg ZL, Lakhani S, Ho S, Kleinman HK and Larsen M: Gene expression profiles of mouse submandibular gland development: FGFR1 regulates branching morphogenesis in vitro through BMP- and FGF-dependent mechanisms. Development 129: 5767-5778, 2002.

10. Jaskoll T, Zhou YM, Chai Y, Makarenkova HP, Collinson JM, West JD, Hajihosseini MK, Lee J and Melnick M: Embryonic submandibular gland morphogenesis: Stage-specific protein localization of FGFs, BMPs, Pax6 and Pax9 in normal mice and abnormal SMG phenotypes in FgfR2-IIIc(+/Delta), BMP7(-/-) and Pax6(-/-) mice. Cells Tissues Organs 170: 83-98, 2002.
11. Tagliabracci VS, Engel JL, Wen J, Wiley SE, Worby CA, Kinch LN, Xiao J, Grishin NV and Dixon JE: Secreted kinase phosphorylates extracellular proteins that regulate biomineralization. Science 336: 1150-1153, 2012.

12. Hao J, Narayanan K, Muni T, Ramachandran A and George A: Dentin matrix protein 4 , a novel secretory calcium-binding protein that modulates odontoblast differentiation. J Biol Chem 282: 15357-15365, 2007.

13. Ishikawa HO, Xu A, Ogura E, Manning G and Irvine KD: The Raine syndrome protein FAM20C is a Golgi kinase that phosphorylates bio-mineralization proteins. PLoS One 7: e42988, 2012.

14. George A and Veis A: Phosphorylated proteins and control over apatite nucleation, crystal growth, and inhibition. Chem Rev 108: 4670-4693, 2008.

15. Tagliabracci VS, Xiao J and Dixon JE: Phosphorylation of substrates destined for secretion by the Fam 20 kinases. Biochem Soc Trans 41: 1061-1065, 2013.

16. Tagliabracci VS, Wiley SE, Guo X, Kinch LN, Durrant E, Wen J, Xiao J, Cui J, Nguyen KB, Engel JL, et al: A Single Kinase Generates the Majority of the Secreted Phosphoproteome. Cell 161: 1619-1632, 2015.

17. Simpson MA, Hsu R, Keir LS, Hao J, Sivapalan G, Ernst LM, Zackai EH, Al-Gazali LI, Hulskamp G, Kingston HM, et al: Mutations in FAM20C are associated with lethal osteosclerotic bone dysplasia (Raine syndrome), highlighting a crucial molecule in bone development. Am J Hum Genet 81: 906-912, 2007.

18. Acevedo AC, Poulter JA, Alves PG, de Lima CL, Castro LC, Yamaguti PM, Paula LM, Parry DA, Logan CV, Smith CE, et al: Variability of systemic and oro-dental phenotype in two families with non-lethal Raine syndrome with FAM20C mutations. BMC Med Genet 16: 8, 2015.

19. Seidahmed MZ, Alazami AM, Abdelbasit OB, Al Hussein K, Miqdad AM, Abu-Sa'da O, Mustafa T, Bahjat S and Alkuraya FS: Report of a case of Raine syndrome and literature review. Am J Med Genet A 167A: 2394-2398, 2015.

20. Raine J, Winter RM, Davey A and Tucker SM: Unknown syndrome: Microcephaly, hypoplastic nose, exophthalmos, gum hyperplasia, cleft palate, low set ears, and osteosclerosis. J Med Genet 26: 786-788, 1989.

21. Wang X, Hao J, Xie Y, Sun Y, Hernandez B, Yamoah AK, Prasad M, Zhu Q, Feng JQ and Qin C: Expression of FAM20C in the osteogenesis and odontogenesis of mouse. J Histochem Cytochem 58: 957-967, 2010.

22. Du EX, Wang XF, Yang WC, Kaback D, Yee SP, Qin CL, George A and Hao JJ: Characterization of Fam20C expression in odontogenesis and osteogenesis using transgenic mice. Int J Oral Sci 7: 89-94, 2015.

23. Wang X, Wang S, Lu Y, Gibson MP, Liu Y, Yuan B, Feng JQ and Qin C: FAM20C plays an essential role in the formation of murine teeth. J Biol Chem 287: 35934-35942, 2012.

24. Vogel P, Hansen GM, Read RW, Vance RB, Thiel M, Liu J, Wronski TJ, Smith DD, Jeter-Jones S and Brommage R: Amelogenesis imperfecta and other biomineralization defects in Fam20a and Fam20c null mice. Vet Pathol 49: 998-1017, 2012.

25. Tibaldi E, Arrigoni G, Brunati AM, James P and Pinna LA: Analysis of a sub-proteome which co-purifies with and is phosphorylated by the Golgi casein kinase. Cell Mol Life Sci 63: 378-389, 2006.

26. Jernvall $\mathbf{J}$ and Thesleff I: Reiterative signaling and patterning during mammalian tooth morphogenesis. Mech Dev 92: 19-29, 2000.

27. Wagner KU, McAllister K, Ward T, Davis B, Wiseman R and Hennighausen L: Spatial and temporal expression of the Cre gene under the control of the MMTV-LTR in different lines of transgenic mice. Transgenic Res 10: 545-553, 2001.

28. Ewald D, Li M, Efrat S, Auer G, Wall RJ, Furth PA and Hennighausen L: Time-sensitive reversal of hyperplasia in transgenic mice expressing SV40 T antigen. Science 273: 1384-1386, 1996.

29. Wagner KU, Wall RJ, St-Onge L, Gruss P, Wynshaw-Boris A, Garrett L, Li M, Furth PA and Hennighausen L: Cre-mediated gene deletion in the mammary gland. Nucleic Acids Res 25: 4323-4330, 1997.

30. Wang X, Wang S, Li C, Gao T, Liu Y, Rangiani A, Sun Y, Hao J, George A, Lu Y, et al: Inactivation of a novel FGF23 regulator, FAM20C, leads to hypophosphatemic rickets in mice. PLoS Genet 8: e1002708, 2012.

31. Livak KJ and Schmittgen TD: Analysis of relative gene expression data using real-time quantitative PCR and the 2(-Delta Delta C(T)) method. Methods 25: 402-408, 2001. 
32. Romanenko VG, Nakamoto T, Srivastava A, Begenisich T and Melvin JE: Regulation of membrane potential and fluid secretion by $\mathrm{Ca}^{2+}$-activated $\mathrm{K}^{+}$channels in mouse submandibular glands. J Physiol 581: 801-817, 2007.

33. Nalbant D, Youn H, Nalbant SI, Sharma S, Cobos E, Beale EG, Du Y and Williams SC: FAM20: An evolutionarily conserved family of secreted proteins expressed in hematopoietic cells. BMC Genomics 6: 11, 2005.

34. Gresik EW: The granular convoluted tubule (GCT) cell of rodent submandibular glands. Microsc Res Tech 27: 1-24, 1994.

35. Ma T, Song Y, Gillespie A, Carlson EJ, Epstein CJ and Verkman AS: Defective secretion of saliva in transgenic mice lacking aquaporin-5 water channels. J Biol Chem 274 20071-20074, 1999.

36. Krane CM, Melvin JE, Nguyen HV, Richardson L, Towne JE, Doetschman $\mathrm{T}$ and Menon AG: Salivary acinar cells from aquaporin 5-deficient mice have decreased membrane water permeability and altered cell volume regulation. J Biol Chem 276 : 23413-23420, 2001.

37. Penschow JD, Drinkwater CC, Haralambidis J and Coghlan JP: Sites of expression and induction of glandular kallikrein gene expression in mice. Mol Cell Endocrinol 81: 135-146, 1991.

38. Smith FJ, Porter RM, Corden LD, Lunny DP, Lane EB and McLean WH: Cloning of human, murine, and marsupial keratin 7 and a survey of K7 expression in the mouse. Biochem Biophys Res Commun 297: 818-827, 2002.

39. Melnick M and Jaskoll T: Mouse submandibular gland morphogenesis: A paradigm for embryonic signal processing. Crit Rev Oral Biol Med 11: 199-215, 2000.

40. Jaskoll T, Chen H, Min Zhou Y, Wu D and Melnick M: Developmental expression of survivin during embryonic submandibular salivary gland development. BMC Dev Biol 1: 5 , 2001.

41. Fiaschi M, Kolterud A, Nilsson M, Toftgård R and Rozell B: Targeted expression of GLI1 in the salivary glands results in an altered differentiation program and hyperplasia. Am J Pathol 179: 2569-2579, 2011.

42. Barka T: Biologically active polypeptides in submandibular glands. J Histochem Cytochem 28: 836-859, 1980.

43. Yoshida S, Ohbo K, Takakura A, Takebayashi H, Okada T, Abe K and Nabeshima Y: Sgn1, a basic helix-loop-helix transcription factor delineates the salivary gland duct cell lineage in mice. Dev Biol 240: 517-530, 2001.
44. Yamagishi R, Wakayama T, Nakata H, Adthapanyawanich K, Kumchantuek T, Yamamoto $\mathrm{M}$ and Iseki S: Expression and localization of alpha-amylase in the submandibular and sublingual glands of mice. Acta Histochem Cytochem 47: 95-102, 2014.

45. Marchetti L, Gabrielli MG, Materazzi G and Menghi G: Cellular compartmentation of lysozyme and alpha-amylase in the mouse salivary glands. Immunogold approaches at light and electron microscopy level. Histol Histopathol 15: 337-346, 2000.

46. Menghi G, Marchetti L, Bondi AM, Accili D, Sabbieti MG and Materazzi G: Double-sided staining with a gold probe and silver enhancement to detect alpha-amylase and sugar moieties in the mouse salivary glands. Histol Histopathol 14: 687-695, 1999.

47. Smith RJ and Frommer J: Effects of prepubertal castration on development of granular tubules and amylase activity in the male mouse submandibular gland. Arch Oral Biol 17: 1561-1571, 1972.

48. Gresik EW: The postnatal development of the sexually dimorphic duct system and of amylase activity in the submandibular glands of mice. Cell Tissue Res 157: 411-422, 1975.

49. Morgan-Bathke M, Lin HH, Chibly AM, Zhang W, Sun X, Chen CH, Flodby P, Borok Z, Wu R, Arnett D, et al: Deletion of ATG5 shows a role of autophagy in salivary homeostatic control. J Dent Res 92: 911-917, 2013.

50. Deretic V, Jiang S and Dupont N: Autophagy intersections with conventional and unconventional secretion in tissue development, remodeling and inflammation. Trends Cell Biol 22: 397-406, 2012.

51. Dikeakos JD and Reudelhuber TL: Sending proteins to dense core secretory granules: Still a lot to sort out. J Cell Biol 177: 191-196, 2007.

52. Musselmann K, Green JA, Sone K, Hsu JC, Bothwell IR, Johnson SA, Harunaga JS, Wei Z and Yamada KM: Salivary gland gene expression atlas identifies a new regulator of branching morphogenesis. J Dent Res 90: 1078-1084, 2011.

This work is licensed under a Creative Commons Attribution-NonCommercial-NoDerivatives 4.0 International (CC BY-NC-ND 4.0) License. 